\title{
Quantitatively deciphering paleostrain from digital outcrops model and its application in the eastern Tian Shan, China ${ }^{\star}$
}

\author{
Xin Wang ${ }^{\mathrm{a}}$, Feng Gao ${ }^{\mathrm{a}, *}$ \\ ${ }^{a}$ State Key Laboratory for Geomechanics and Deep Underground Engineering, China University of Mining \\ and Technology, Xuzhou 221116, China
}

\begin{abstract}
The knowledge of the strain/stress field evolution in time is fundamental to the understanding of the earth dynamic system. Based on the principle that past tectonic stress should have left traces in the rocks, geologists have been trying to determine the paleostress history from evidence found in rocks for decades. Recent development of techniques for automatic extraction of fracture surfaces from digital outcrop models and estimation of historical shear deformation on rock fractures provide an efficient way of quantitatively acquiring large amounts of high quality fracture/fault slip data from outcrops. Unlike traditional paleostress inversion methods whose data is manually collected in the field, the new techniques provide much more detailed information about the strain of the outcrop and a good opportunity to develop quantitative methods for deciphering more realistic paleostrains. In this study, instead of fitting the slip data from several fractures to calculate the overall strain tensor, the local strain tensor is calculated for slip on each fracture from the outcrop. Then the local strain tensors are grouped into populations corresponding to different strain events using a clustering analysis technique. Theoretical advantages of this new method over the traditional ones are discussed. The applications on outcrops in the eastern Tian Shan area give a clear picture of the late Cenozoic paleostrain variation over space and time, and also throw light on the cause for the change in the strain regime in time, the fracture development
\end{abstract}

\footnotetext{
${ }^{\star}$ Code available from: https://github.com/EricAlex/structrock.

${ }^{*}$ Corresponding author

Email address: ericrussell@zju.edu.cn (Xin Wang)
} 
patterns and the distribution of shear displacements in fracture networks.

Keywords:

Paleostrain; Quantitative methods; Digital outcrops model; Strain tensor; Clustering analysis; Eastern Tian Shan

\section{Introduction}

The deformation of the surface and subsurface of the Earth and other planetary bodies reflects past changes in local and regional stress and strain, and can be used to reconstruct past crustal movements and dynamics. Paleostress analysis is a branch of structural geology whose target is characterizing stress systems acting in the past from their record in deformation structures, singularly from faultslip data (Simón, 2019), based on the principle that past tectonic stress should have left traces in the rocks (Hancock, 1985). Since the first introduction of the paleostress inversion methods by Wallace (1951) and Bott (1959), it has been developed worldwide during the last decades (e.g., Angelier, 1979; Angelier et al., 1982; Angelier, 1984, 1989, 1990; Delvaux et al., 1997; Twiss and Unruh, 1998; Kaven et al., 2011; Stipp and Tullis, 2003; Shimizu, 2008), and several thousands of paleostress reconstructions have been carried out in all tectonic settings (e.g., Homberg et al., 1999, 2002; Lacombe et al., 2006; Amrouch et al., 2010, 2011; Arboit et al., 2015; Radaideh and Melichar, 2015; Riller et al., 2017; Hashimoto et al., 2019; Maestro et al., 2019). In the opinion of Simón (2019), "perhaps no other branch of structural analysis offers such a high number of methods and is submitted to such an intense conceptual discussion”.

However, the debate is not closed, and the critiques are mainly concerning that conventions on which the inversion methods depend do not apply in the real world. For example, in the basic assumptions for paleostress analysis (e.g., Etchecopar et al., 1981), the assumption that "the stress state is homogeneous within the studied rock body" ignores local stress perturbations caused by discontinuities in the rock body; the assumption that "all fault slips are related to a single stress tensor" ignores the fact that faults are usually the results of multiple tectonic events, hence multiple stress tensors; the assumption that "blocks bounded 
by the fault planes are rigid and show no significant rotation" ignores the fact that strata are usually tilted; and the assumption that "movement on each fault is independent of the other ones" ignores the fact that faults interactions are quite common. Other researchers who recently have called for a cautious and critical attitude are complaining about the lack of parameters for assessing the quality of the field data as well as the paleostress inversion results (e.g., Sperner and Zweigel, 2010; Hippolyte et al., 2012; Lacombe, 2012; Simón, 2019).

Now there may be a chance to solve the above problems, benefiting from recent development of techniques for automatic extraction of fracture surfaces from digital outcrop models (Wang et al., 2017) and estimation of historical shear deformation on rock fractures (Wang et al., 2019), which provide an efficient way of quantitatively acquiring large amounts of high quality fracture/fault slip data from outcrops. Usually thousands of fracture/fault slip data can be extracted from just one single outcrop. In those methods, an extra parameter that quantifies the relative amount of slip indicators (fault striations and steps) can also serve as a measure of the quality of the fracture/fault slip data, and the great amount of high quality data gives an opportunity to get rid of those to some extent controversial assumptions.

In this paper, building upon large amounts of high quality fracture/fault slip data, we propose an approach for quantitatively deciphering paleostrain from the digital outcrops model. The only assumption our method adopted is that fault displacements are small with respect to fault dimensions. For each fracture from an outcrop, the slip displacement on it results in a strain, hence a Lagrangian strain tensor, of the local rock body that tightly encloses that fracture. For a population of Lagrangian strain tensors in the outcrop, we perform a clustering analysis on their principal shortening directions to obtain the tectonic shortening events experienced by the outcrop, both far-field and local. Theoretical advantages of this new method over the traditional ones are discussed. The applications of our method on outcrops from the eastern Tian Shan area give a clear picture of the late Cenozoic paleostrain variation over space and time, and throw light on the cause for the change in the strain regime in time, the fracture development patterns and the distribution 
of shear displacements in fracture/fault networks.

\section{The study area and the digital outcrop datasets}

The study area is located at the eastern Tian Shan, China, which is bounded by the Junggar Basin in the North and the Tarim Basin in the South, as shown in Fig. 1. Tian Shan is one of the prominent active mountain ranges in central Asia. It is created by two late Paleozoic suture zones (northern and southern Tian Shan suture zones) (e.g., Windley et al., 1990; Allen et al., 1993), and has been reactivated since the India-Eurasia collision in the Cenozoic (e.g., Molnar and Tapponnier, 1975; Tapponnier and Molnar, 1979), which makes it an ideal area for rock fracture system development and tectonic paleostrain researches.

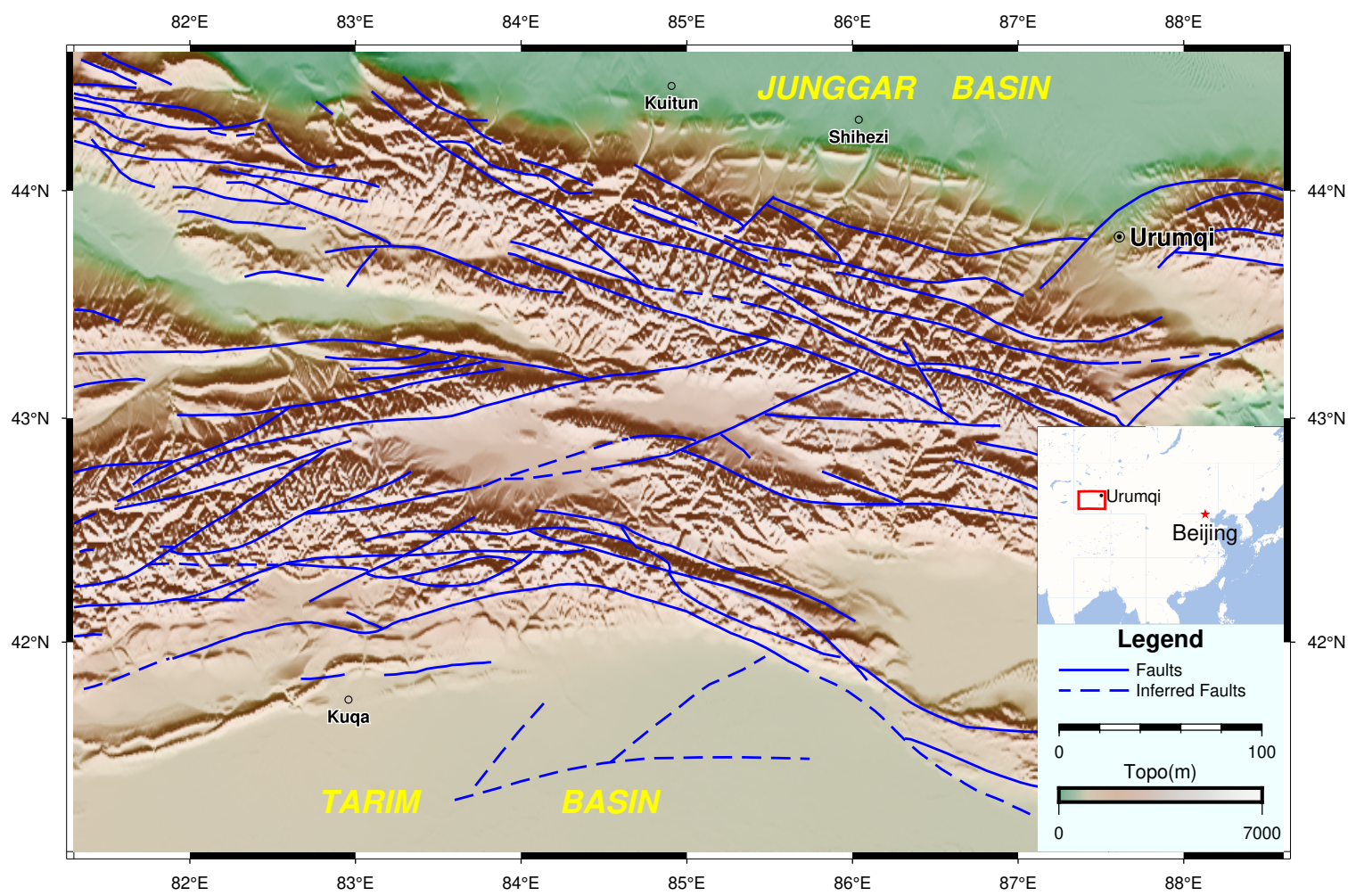

Figure 1: The study area: eastern Tian Shan, China. The faults are modified after Ma et al. (2002).

Belts of folding and thrusting is the main tectonic feature in the eastern Tian Shan area, in which the Cenozoic formations are detached from the underlying formations and form a series of EW-trending folds (e.g., Molnar et al., 1994). The Tian Shan Mountains propagated 
outward and rose progressively as wedge-shaped blocks (Yang et al., 2008). The current (1992 to 2006) crustal movement velocity field presented by Yang et al. (2008) reveals that $80 \%-90 \%$ of the N-S shortening was absorbed by young faults along the southern and northern edges, and relatively little deformation was accommodated by reactivated faults within the interior.

Seismic activities are widely recorded within the eastern Tian Shan (Fu et al., 2003). The area has recorded two large earthquakes (Atushi, $M \geq 8.2$, August 22, 1902; Manas, M $=8.3$, December 23, 1906) and five moderate earthquake events $(M \geq 7)$ during the 20th century (e.g., Molnar and Deng, 1984; Molnar and Ghose, 2000). It indicates that the Tian Shan is presently a seismically active range $(\mathrm{Ni}, 1978)$.

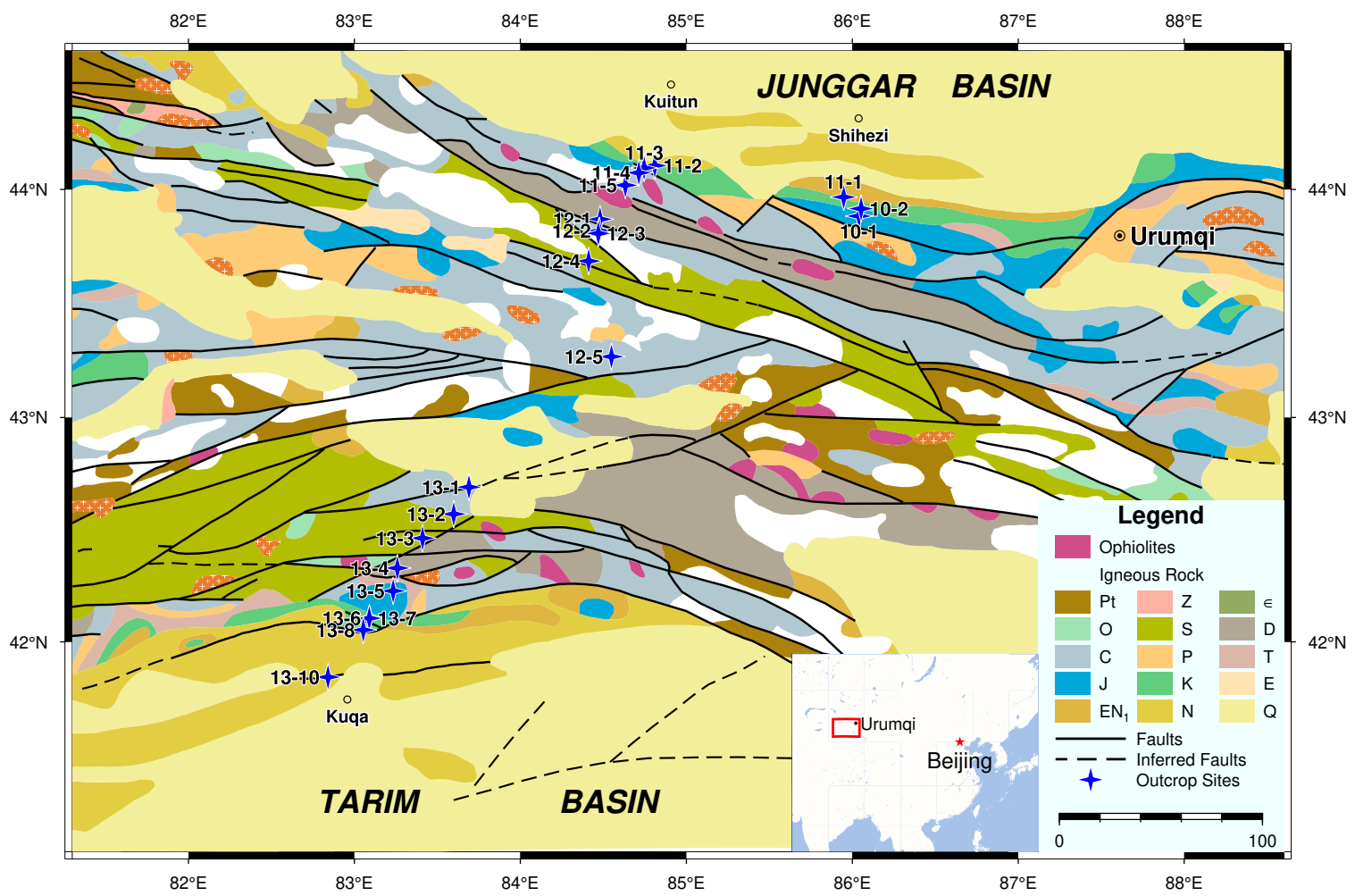

Figure 2: Geological map (modified after Ma et al. (2002)) of the study area. Outcrop sites where we acquired digital outcrop datasets are marked with blue quadrangular stars.

The blue quadrangular stars with black labels shown in the geological map of the study area (Fig. 2) mark locations of outcrop sites where we acquired digital outcrop datasets 
(point clouds). As shown in Fig. 2, apart from considering the exposure conditions of the fracture surfaces and the spatially even distribution of the outcrop sites, we tried to choose outcrops from different stratigraphic eras whose corresponding formations are exposed in the eastern Tian Shan area, in an effort to analyze the paleostrain in space and time. 21 outcrop sites were surveyed to acquire the digital outcrop datasets. The datasets are numbered using labels shown in Fig. 2.

\section{Methodology}

\subsection{The fracture/fault slip data derived from digital outcrops and its quality assessment}

The fracture/fault slip data is derived from digital outcrops using method proposed by Wang et al. (2019). Basically, this method analyzes the anisotropy of the fracture surface morphology caused by slip displacement on fracture surfaces that are automatically extracted from the digital outcrop, and then estimate the slip direction, as well as the relative amount of slip indicators (fault striations and steps). A region-growing approach proposed by Wang et al. (2017) is used for automatically extracting fracture surfaces from the digital outcrop, and of course the fracture surfaces need to be exposed on outcrops to be measured and extracted. The relative amount of slip indicators may also serve as a good measure of the quality of the fracture/fault slip data, which according to Hippolyte et al. (2012), has a primary influence on the quality of the stress inversion results. For a more rigorous and detailed description of this method please see Wang et al. (2019), here we mainly discuss its quality assessment. Usually thousands of fracture surfaces, hence fracture/fault slip data, can be extracted from just one single outcrop, and much more detailed information about the strain of the outcrop can be provided by this large amounts of data than traditional paleostress inversion methods whose data is manually collected in the field. The detailed information about the strain of the outcrop also shows that some of the assumptions of the traditional paleostress inversion methods are problematic as will be discussed later in the application examples. 
Wang et al. (2019) defined the terms "quasi striations" and "quasi steps" to refer to slip indicators that are causing similar anisotropy of the fracture surface morphology as the traditional fault striations and fault steps do, whether they can be obviously seen on the fracture surface or not. A parameter $\theta_{\max }^{*} / C$ that describes the contribution of fracture surface morphology on the shear strength was proposed by Grasselli et al. (2002). A theoretical model that describes the contribution of slip indicators on the shear strength considers the effect of surface morphology as a combination of three components: the base effect $B$ of isotropic morphology (e.g., joints with no slip indicators on it), the effect of "quasi striations" $M_{f}$ that decreases the shear strength along its slip direction and the effect of "quasi steps" $M_{g}$ that increases the shear strength along direction that faces the steps. Wang et al. (2019)'s method essentially fits the theoretical model to $\theta_{\text {max }}^{*} / C$ from the surface morphology of a real fracture and estimates the directions and the amount of quasi striations $M_{f} / B$ and quasi steps $M_{g} / B$ : the combination of directions of quasi striations and quasi steps determine the slip direction on the fracture surface, while the quality of those estimations depends on the amount of slip indicators (quasi striations and quasi steps). However, the fracture surface morphology is also influenced by erosion, lithology, etc., and that's the reason why the quality assessment of the fracture/fault slip data and the handling of error and noise in the data are very important. How the amount of slip indicators influences the quality of the slip direction estimation, and how the amount of slip indicators can serve as an confidence index of the slip direction estimation results, are discussed below.

An experiment was designed to highlight the effects of the amount of slip indicators and to make it the only variable while other factors are kept unchanged. This can be archived by changing the point density of the point cloud covering the same fracture surface, since the amount of slip indicators a point cloud can capture decreases with decreasing point density. Also, to illustrate the quality change of the direction estimation of just one of the slip indicators, such as the quasi striations, a fracture surface with fault striations much less developed than fault steps should be chosen for this experiment, so that only the quasi striations' direction estimation is primarily influenced by the decreasing amount of slip 
indicators, which can be produced by reducing the point density of the point cloud. The results of this experiment are shown in Fig. 3. For a fracture surface whose fault striations are much less developed than fault steps, the point density of the point cloud changed from $2 \mathrm{~mm}$ to $12 \mathrm{~mm}$ for Wang et al. (2019)'s method as illustrated in Fig. 3a. The estimated amount of quasi striations declines as expected with decreasing point density, and when it declines to roughly 0.05 , an instability in the estimation of the occurrence of quasi striations emerges as shown in Fig. 3b (a sign of the emerge of bad quality data). Thus, the amount of quasi striations may serve as an confidence index of the quality of the occurrence estimation for quasi striations. Note that it's primarily the reduction of the amount of quasi striations that causes the occurrence estimation instability, since there isn't obvious and constant decline of the amount of quasi steps as shown in Fig. 3c, and the fact that fault striations are much less developed than fault steps in this experiment makes the estimation of quasi striations' occurrence more prone to instability. Note that the threshold of 0.05 only describes certain degree of fracture surface anisotropy below which the estimation of quasi striations' occurrence may be prone to instability, and it is not related to particular rock type or certain form of fracture surface morphology. So without loss of generality, for the amount of quasi striations, the threshold of 0.05 from this experiment may be applied in future studies in searching for reliable occurrence estimation for quasi striations.

Usually the fault striations show the slip direction more consistently than the fault steps, because of the fault steps' "zigzag" shapes. But the fault striations actually show two opposite directions that are equally possible for the fault to have slipped in. So the sense of slip showed by the fault steps should also be considered to determine the exact slip direction. Let $\phi_{f}$ and $\left[\left(\phi_{f}+\pi\right)(\bmod 2 \pi)\right]$ be the two opposite slip directions that the fault striations show, and $\phi_{g}$ be the sense of slip showed by the fault steps, then the exact slip 
direction $\phi_{S}$ is defined as follows:

$$
\phi_{S}= \begin{cases}\phi_{f} & \text { if }\left|\phi_{f}-\phi_{g}\right|<\pi / 2 \\ \text { undefined } & \text { if }\left|\phi_{f}-\phi_{g}\right|=\pi / 2 \\ \left(\phi_{f}+\pi\right)(\bmod 2 \pi) & \text { if }\left|\left[\left(\phi_{f}+\pi\right)(\bmod 2 \pi)\right]-\phi_{g}\right|<\pi / 2,\end{cases}
$$

which essentially chooses the slip direction from the two opposite slip directions with whom the sense of slip showed by the fault steps agrees more.

Sagy et al. (2007) have shown through the variations in RMS roughness, spectral shape, and 3D geometry that faults evolve with slip toward geometrical simplicity along the slip direction. This means that the degree of fault surface anisotropy is more and more enhanced with the slip. So we use the combination of the amount of quasi striations $\left(M_{f} / B\right)$ and quasi steps $\left(M_{g} / B\right)$, who both describe the degree of fracture surface anisotropy, to estimate the relative slip $\left(M_{S}=M_{f} / B+M_{g} / B\right)$ on the fracture surface. 

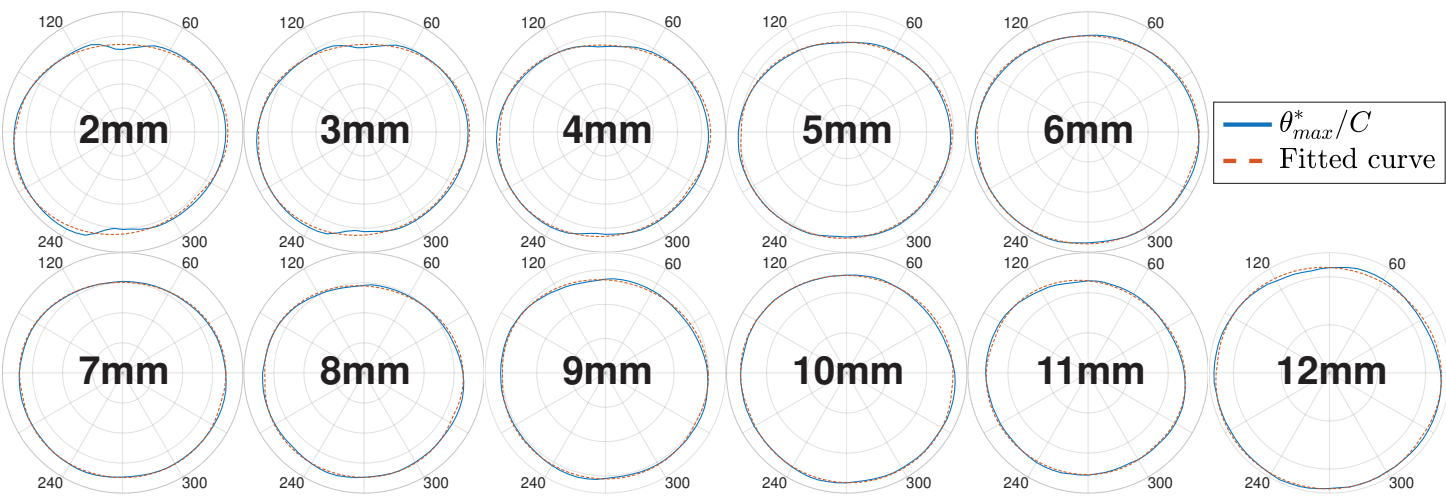

(a)

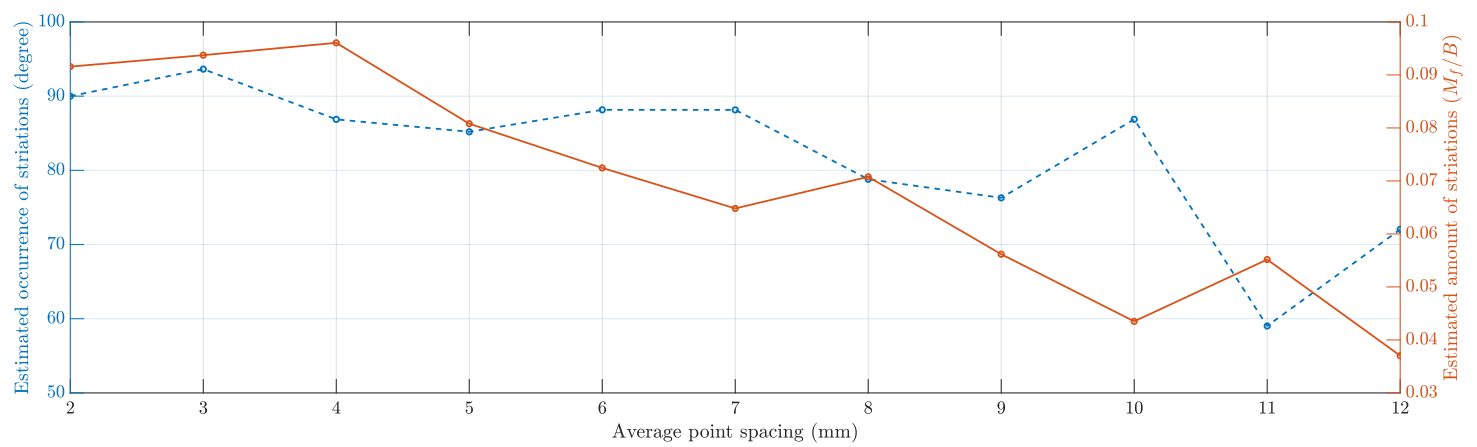

(b)

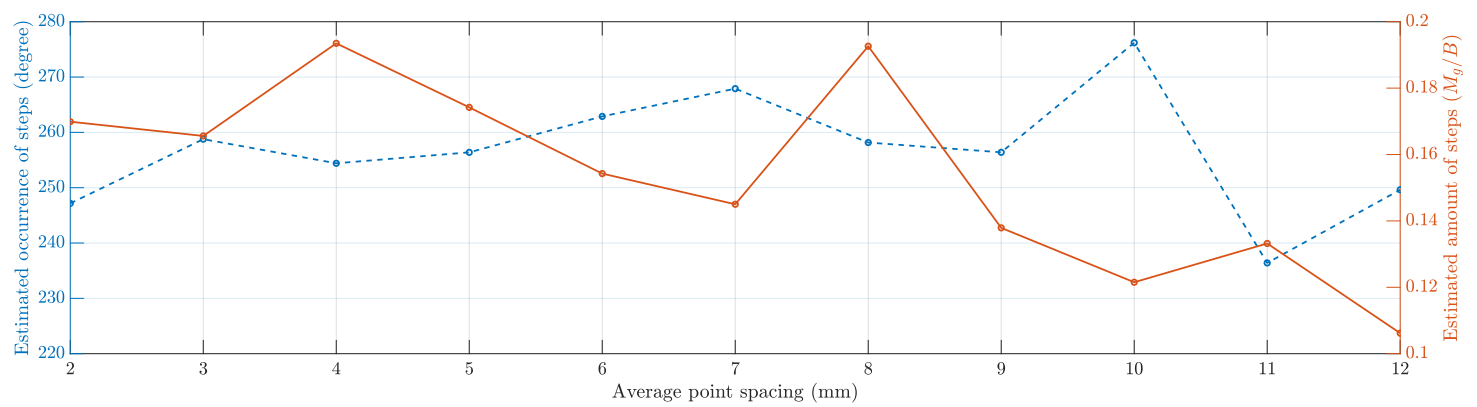

(c)

Figure 3: The experiment to highlight the effects of the amount of slip indicators. (a) For a fracture surface whose fault striations are much less developed than fault steps, the point density of the point cloud changed from $2 \mathrm{~mm}$ to $12 \mathrm{~mm}$, the theoretical model is fitted to $\theta_{\text {max }}^{*} / C$ from the surface morphology of this fracture to estimate the occurrence and the amount of quasi striations $M_{f} / B$ and quasi steps $M_{g} / B . \theta_{\text {max }}^{*} / C$ and the fitted curve are polar plotted against all the possible slip directions on the fracture plane. (b) The estimated amount of quasi striations and the occurrence of quasi striations plotted against the point density. (c) The estimated amount of quasi steps and the occurrence of quasi steps plotted against the point density. 


\subsection{The Lagrangian strain tensor resulted from the slip on a fracture}

The slip on the fracture surface accommodates the local strain of the rock mass which have undergone tectonic deformations, and is usually the result of one to several tectonic deformation events. If the only assumption in our method, that fault displacements are small with respect to fault dimensions, is true, as shown in Fig. 4, the small slip displacement $\mathbf{u}$ on the fracture surface can be simplified as simple shear as illustrated by the red dashed lines. In this setting, $\mathbf{e}_{1}$ is the unit vector of axis $X_{1}$, and the slip vector $\mathbf{u}=k \mathbf{e}_{1}$, i.e., there is a slip distance $k$ along the axis $X_{1} ; \mathbf{e}_{2}$ is the unit vector of axis $X_{2}$, and also the normal vector of the fracture surface; $\mathbf{e}_{3}$ is the unit vector of axis $X_{3}$. We use the estimated relative slip $M_{S}=M_{f} / B+M_{g} / B$ described in Section 3.1 to define the slip distance $k=\zeta M_{S}$, in which the coefficient $\zeta$ is to make sure that the slip distance $k$ is relatively small with respect to the fracture dimension. In our cases, $M_{S}$ usually has a maximum value around 0.6 , and we set $\zeta$ to 0.2 to keep $k$ in the range of $(0,0.12)$. 


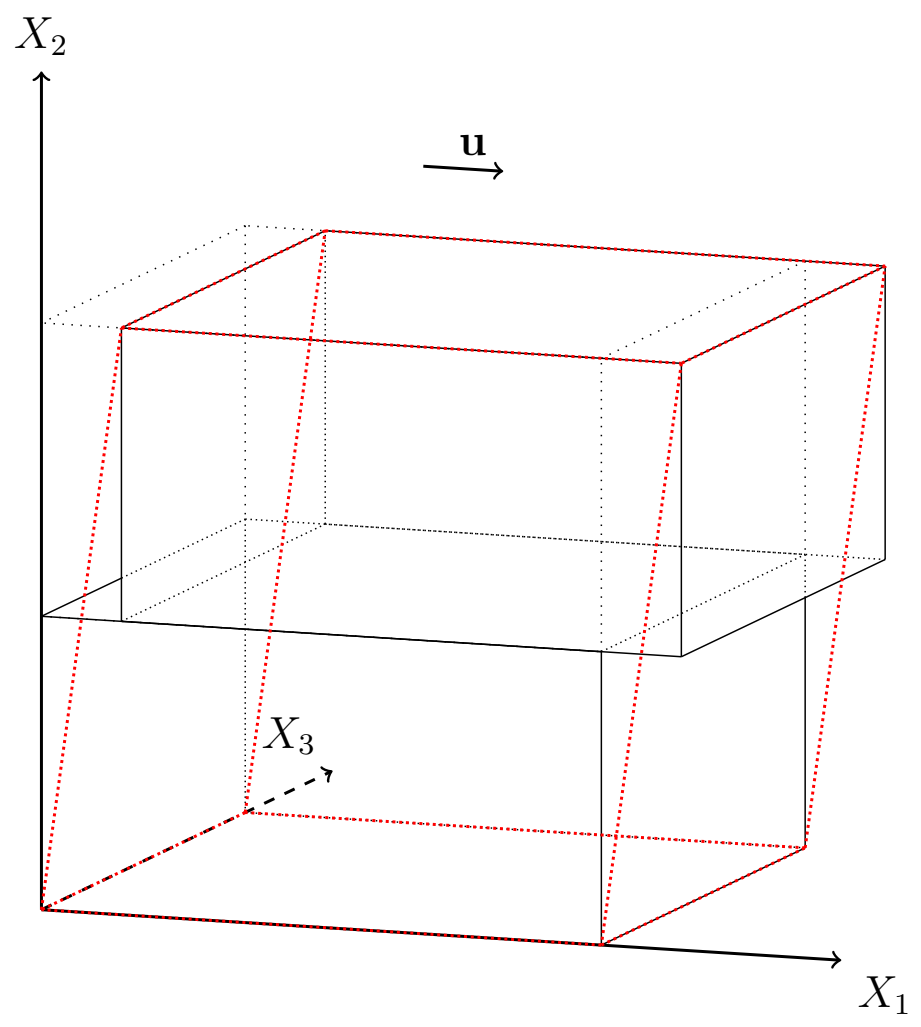

Figure 4: The illustration of a small slip displacement $\mathbf{u}$ on the fracture surface and the simplified simple shear (red dashed lines).

In this simplified simple shear model, the displacement $\mathbf{u}(\mathbf{X})$ of the material points have components $u_{1}=k X_{2}, u_{2}=0$ and $u_{3}=0$. The corresponding displacement gradient tensor with respect to the rectangular Cartesian coordinates $\left(\mathbf{X}=X_{i} \mathbf{e}_{i}\right.$ and $\left.\mathbf{u}=u_{i} \mathbf{e}_{i}\right)$ is:

$$
[\nabla \mathbf{u}]=\left[\begin{array}{lll}
0 & k & 0 \\
0 & 0 & 0 \\
0 & 0 & 0
\end{array}\right]
$$


The Lagrangian strain tensor is:

$$
\begin{aligned}
\mathbf{E}^{*} & =\frac{1}{2}\left[\nabla \mathbf{u}+(\nabla \mathbf{u})^{\top}+(\nabla \mathbf{u})^{\top}(\nabla \mathbf{u})\right] \\
& =\left[\begin{array}{ccc}
0 & k / 2 & 0 \\
k / 2 & k^{2} / 2 & 0 \\
0 & 0 & 0
\end{array}\right]
\end{aligned}
$$

Note that the Cartesian coordinate system used here (with standard basis $\left\{\mathbf{e}_{1}, \mathbf{e}_{2}, \mathbf{e}_{3}\right\}$ ) is unique for each fracture and suitable only for describing local deformations around the fracture, since $\mathbf{e}_{2}$ is the normal vector of the fracture surface and $\mathbf{e}_{1}$ is the slip direction on the fracture surface. We need a unified coordinate system in which we can discuss large scale tectonic deformations experienced by the rock mass or even the whole study region, for example, a coordinate system in which $\mathbf{e}_{1}^{\prime}=(1,0,0)$ points east, $\mathbf{e}_{2}^{\prime}=(0,1,0)$ points north and $\mathbf{e}_{3}^{\prime}=(0,0,1)$ points vertically up. The transformation matrix that transforms the expression of the Lagrangian strain tensor from the coordinate system with standard basis $\left\{\mathbf{e}_{1}, \mathbf{e}_{2}, \mathbf{e}_{3}\right\}$ to the coordinate system with standard basis $\left\{\mathbf{e}_{1}^{\prime}, \mathbf{e}_{2}^{\prime}, \mathbf{e}_{3}^{\prime}\right\}$ is:

$$
\mathbf{T}=\left[\begin{array}{lll}
\mathbf{e}_{1} \cdot \mathbf{e}_{1}^{\prime} & \mathbf{e}_{1} \cdot \mathbf{e}_{2}^{\prime} & \mathbf{e}_{1} \cdot \mathbf{e}_{3}^{\prime} \\
\mathbf{e}_{2} \cdot \mathbf{e}_{1}^{\prime} & \mathbf{e}_{2} \cdot \mathbf{e}_{2}^{\prime} & \mathbf{e}_{2} \cdot \mathbf{e}_{3}^{\prime} \\
\mathbf{e}_{3} \cdot \mathbf{e}_{1}^{\prime} & \mathbf{e}_{3} \cdot \mathbf{e}_{2}^{\prime} & \mathbf{e}_{3} \cdot \mathbf{e}_{3}^{\prime}
\end{array}\right]
$$

And the expression of the Lagrangian strain tensor is transformed as:

$$
\mathbf{E}^{*^{\prime}}=\mathbf{T}^{\top} \mathbf{E}^{*} \mathbf{T}
$$

\subsection{The clustering analysis of the principal shortening directions of the Lagrangian strain} tensors

The paleostrain of the rock mass at the scale of outcrops is to some extent accommodated and hence recorded by the slip on certain groups of fractures. In one particular paleostrain event, the local Lagrangian strain tensors resulted from the slip on those fractures are 
constrained and contributing to the body strain of the rock mass, and hence should tend to be similar, instead of canceling out each other's effect on the rock mass. This enables the analysis of paleostrains experienced by the outcrop through a clustering analysis of the Lagrangian strain tensors resulted from the slip on fractures of this outcrop.

To simplify the clustering analysis, the Lagrangian strain tensor $\mathbf{E}^{*^{\prime}}$, in the coordinate system with the standard basis composed of its three principal strain directions $\left\{\mathbf{n}_{1}, \mathbf{n}_{2}, \mathbf{n}_{3}\right\}$, can be written in its diagonal form:

$$
\left[\mathbf{E}^{*^{\prime}}\right]_{\mathbf{n}_{i}}=\left[\begin{array}{ccc}
E_{1} & 0 & 0 \\
0 & E_{2} & 0 \\
0 & 0 & E_{3}
\end{array}\right]
$$

in which $E_{1}, E_{2}$ and $E_{3}$ are the unit elongations along the principal directions $\mathbf{n}_{1}, \mathbf{n}_{2}$ and $\mathbf{n}_{3}$ respectively, and also the eigenvalues of $\mathbf{E}^{*^{\prime}}$, or principal strains. In the equivalent simple shear model shown as red dashed lines in Fig. 4, the principal strains are shortening, zero and elongation. Let's say $E_{1}<0, E_{2}=0$ and $E_{3}>0$, we will use the principal shortening direction $\mathbf{n}_{1}$ to do the clustering analysis since the slip on fractures is more directly associated with shortening of the rock mass in certain direction, while the principal elongation direction $\mathbf{n}_{3}$ can be used to further distinguish paleostrain events based on the results of the clustering analyses.

A clustering algorithm called density-based spatial clustering of applications with noise (DBSCAN) is used for the clustering analysis of the principal shortening directions $\left\{\mathbf{n}_{1}^{i}\right\}$. DBSCAN, proposed by Ester et al. (1996), is one of the most common clustering algorithms and also one of the most cited data mining algorithms in scientific literature. Given a set of points in some space, DBSCAN groups together points that are closely packed (points with many nearby neighbors), and marks outlier points that lie alone in low-density regions (whose nearest neighbors are too far away). The true conditions of the rock fractures in the nature are always more complex than we can exhaustively consider, so the methods we used to automatically extract fracture surfaces from digital outcrop models and estimate historical shear deformation on rock fractures will inevitability introduce noise to the data. 
A clustering algorithm that is robust to noise such as the DBSCAN algorithm is crucial to our analyses.

We need to define the "distance" or similarity between two principal shortening directions to perform the clustering analysis. For any two principal shortening directions $\mathbf{n}_{1}^{i}$ and $\mathbf{n}_{1}^{j}, i \neq j$, the angle between them is $\theta_{i j}=\cos ^{-1}\left[\left(\mathbf{n}_{1}^{i} \cdot \mathbf{n}_{1}^{j}\right) /\left(\left\|\mathbf{n}_{1}^{i}\right\|\left\|\mathbf{n}_{1}^{j}\right\|\right)\right]$, we define the distance between $\mathbf{n}_{1}^{i}$ and $\mathbf{n}_{1}^{j}$ as:

$$
D\left(\mathbf{n}_{1}^{i}, \mathbf{n}_{1}^{j}\right)= \begin{cases}\theta_{i j} & \text { if } \theta_{i j} \leq \pi / 2 \\ \pi-\theta_{i j} & \text { if } \theta_{i j}>\pi / 2\end{cases}
$$

Two parameters are required by DBSCAN: the radius of a neighborhood with respect to some point $(\epsilon)$ and the minimum number of points required to form a dense region (minPts). They can be adjusted according to the distribution characteristics of the data. In our cases, the used values of $\epsilon$ are in the range of $\left(14^{\circ}, 20^{\circ}\right)$ and the used values of minPts are in the range of 10-30 points for most of the outcrops.

\section{Results and discussions}

The digital outcrop datasets that we acquired from the eastern Tian Shan area as described in Section 2 are processed using the proposed method. The clusters of paleostrain shortening directions are shown in poles plots, and their corresponding fracture surfaces, which group into populations reflecting similar shortening directions, are shown on the outcrops with different colors assigned to different clusters/groups, along with the poles plots of the corresponding fracture surfaces' occurrences (Table 1). The clusters of paleostrain shortening directions from each outcrop are also linked to the corresponding outcrop locations on the geological map, as shown in Fig. 5, in order to analyze the deciphered paleostrains in space.

The first thing worth noting is that, for all of the outcrops, the shortening directions indicated by most of the fracture surfaces do tend to cluster into groups reflecting paleostrain events experienced by the outcrop rock mass. In addition, there seems to be some degree 
of consistency in the groups of shortening directions through the study region: most of the outcrops show near horizontal N-S shortening groups and near horizontal NE-SW shortening groups, which makes a fairly strong case that they are caused by far-field/regional strain events. And this can be further supported by the fact that the occurrences of their corresponding fracture surfaces are not confined by fracture surfaces of other shortening groups (e.g., 10-2, 11-3, 13-4 from Table 1 and 12-2, 12-3, 13-1 from supporting information Table S1), which means that they are not caused by local strain events. The principal shortening axes of the current geodetic strain rate tensor derived from GPS measurements (e.g., Yang et al., 2008) agrees more with the near horizontal N-S shortening groups, which may imply that this is the shortening directions of the latest shortening events. The near horizontal NE-SW shortening groups may be caused by older shortening events. The occurrences of the tilted bedding surfaces from those outcrops (black arcs in the poles plots) also suggest that they are not tilted just because of the latest shortening events, older shortening events must have occurred. The change of shortening directions over time through the study region from NE-SW to N-S may have left some clues on outcrop 11-4 and $13-10$.

Some of the shortening directions poles plots also show pairs of high angle shortening groups with roughly opposite azimuths. The high angle shortening groups seem to be correlated with one of the horizontal (far-field/regional) shortening groups in the sense of azimuth. The fracture surfaces corresponding to the high angle shortening groups seem to be caused by local strains and confined between fracture surfaces corresponding to the regional shortening groups, which can be clearly seen from outcrop 10-1, 11-1 and 13-4 in Table 1 (more examples can be seen from outcrop 11-4, 11-5 and 13-10 in supporting information Table S1). A model like the Riedel shear structures may be suitable to describe the regional-local strain relationships here. Although there are good reasons to suspect that one of the high angle shortening groups may represent non-tectonic faults (e.g., landslides), a pair of high angle shortening groups with roughly opposite azimuths in one outcrop would mean that this outcrop had landslides toward opposite directions, which is not very likely. 
But a more interesting explanation for the high angle shortening groups is that the strain of the outcrop is resulted from the combined stresses of the near horizontal tectonic stress $\sigma_{H}$ and the vertical stress $\sigma_{V}$ (gravitational force, uplift force, etc.), and when the ratio of $\sigma_{V}$ to $\sigma_{H}$ is reasonably large enough, the upper block of some of the thrusting faults begin to slide down, with the most steeply dipped faults start first. This can be supported by the fact that the occurrences of the fracture surfaces corresponding to the high angle shortening groups are very similar to that of the thrusting fractures corresponding to the horizontal shortening groups such that they could just move in the opposite direction and be grouped into the horizontal shortening groups, but they are almost all slightly more steeply dipped than the thrusting fractures (many examples can be found from Table 1 and the supporting information Table S1).

In space, the high angle shortening groups correlating with the N-S shortening events are more developed near the northern edge of Tian Shan. Suppose the vertical stress $\sigma_{V}$ are similar between the northern edge and the southern edge of Tian Shan, then the current horizontal tectonic stress $\sigma_{H}$ near the northern edge must be samller than that of the southern edge of Tian Shan. This conclusion is supported by the fact that the current shortening rate near the northern edge is smaller than that of the southern edge of Tian Shan (e.g., Yang et al., 2008; Zubovich et al., 2010, etc.).

The fact that the Neogene outcrops are also affected by the NE-SW shortening events means that the change in the strain regime must happened after the Neogene. In time, the high angle shortening groups correlating with the N-S shortening events are more developed than that correlating with the NE-SW shortening events, and that could both be the result of the decrease of $\sigma_{H}$ or the increase of $\sigma_{V}$ over time. However, the decrease of $\sigma_{H}$ can not explain the rotation of the shortening directions from NE-SW to N-S, and Qiao et al. (2017) identifies a rapid increase in sedimentation rate after 2.6 Ma that could be related to the uplift of Tian Shan, i.e. the increase of $\sigma_{V}$. Beneath the northwest of Lake IssykKul, Tian et al. (2010) indicates that there may be a smallscale hot upwelling from the lower mantle that vertically drives the uplift of Tian Shan. Delvaux et al. (2013) bserved 
a variation of paleostress directions in time in western Tian Shan, from NW-SE $S_{H \max }$ during the late Pliocene-early Pleistocene to N-S since the Middle Pleistocene. Using finite element modelling, Vergnolle et al. (2007) showed that the present-day deformation in the Himalayas, Tibet, Tien Shan and Altai where NS shortening prevails can be explained by the buoyancy forces generated by integrating the gravitational potential energy gradients (GPE) in Asia, the forces provided by the convergence of oceanic plates towards Eurasia and oceanic subduction coupling. They concluded that buoyancy forces alone or forces related to the India-Eurasia collision alone are insufficient to explain the present-day deformation and demonstrated that both contribute in a significant and comparable way. As the GPE distribution in Asia is strongly influenced by the Tibet plateau, Delvaux et al. (2013) propose that the observed stress change could be related to the dynamics of the Tibet plateau uplift. From evidences presented by this research and previous researches, we further propose that the strain regime change since the Middle Pleistocene could be related to the Tian Shan uplift since early Pleistocene.

Although the current crustal movement velocity field presented by Yang et al. (2008) reveals that $80 \%-90 \%$ of the N-S shortening was absorbed by young faults along the southern and northern edges, and relatively little deformation was accommodated by reactivated faults within the interior, the characteristics of the regional strains are very well recorded in ordinary outcrops all over the study area. This study greatly enriches the data sources available for deciphering paleostrain in various applications. On the other hand, the traditional paleostress inversion methods need a detailed field study (e.g., Dehandschutter et al., 2002), including the deformation style, the kinematic style (direction and sense of movement), the crosscutting relations of fault striations, the stratigraphic correlations, and etc., after the overall geologic framework (e.g. number of paleostress systems, chronological order of successive stress patterns) is understood. The existence of high angle shortening groups shows that the slip will not necessarily occur on the plane of the maximum resolved shear stress as assumed by traditional paleostress inversion methods, but on the existing fault planes. This study get rid of those to some extent controversial assumptions to decipher 
more realistic paleostrains. And in the cases of high angle shortening groups, the stress states are similar, but a slight variation of the fault plane's occurrence may result in opposite slip directions, and traditional paleostress inversion methods would get two vastly different stress states. The inversion from paleostrain to paleostress need to consider more heterogeneous and complex models.

The poles plots of the shortening groups' corresponding fracture surfaces show that both the NE-SW and the N-S shortening events are accommodated by slip on fracture surfaces whose strikes are roughly perpendicular to the shortening directions, which is consistent with the knowledge that thrusting is one of the main tectonic features in the eastern Tian Shan area. From Table 1 we can also see that both the NE-SW and the N-S shortening events use the slips on existing discontinuities like bedding surfaces to accomplish the shortening (e.g., outcrop 10-1, 10-2, 11-3 and 13-4), even when the strikes of the existing discontinuities are not optimal for (perpendicular to) the shortening directions (e.g., outcrop 10-2, 11-3 and 13-4). This may be more energy efficient than creating new fractures to accommodate the shortening.

The last thing worth noting is that, for each outcrop, the estimated relative slip $M_{S}$ on the fracture surfaces can be very well fitted by a Weibull distribution (see outcrop 11-3, 12-1, 13-2 and 13-5 in Fig. 6 for example). This may be ascribed to the variations in local strength which can also be described by a Weibull distribution. The parameters of the Weibull distribution of $M_{S}$ may be related to the energy needed to make slip displacements on those fracture surfaces. Further researches are needed on this subject. 


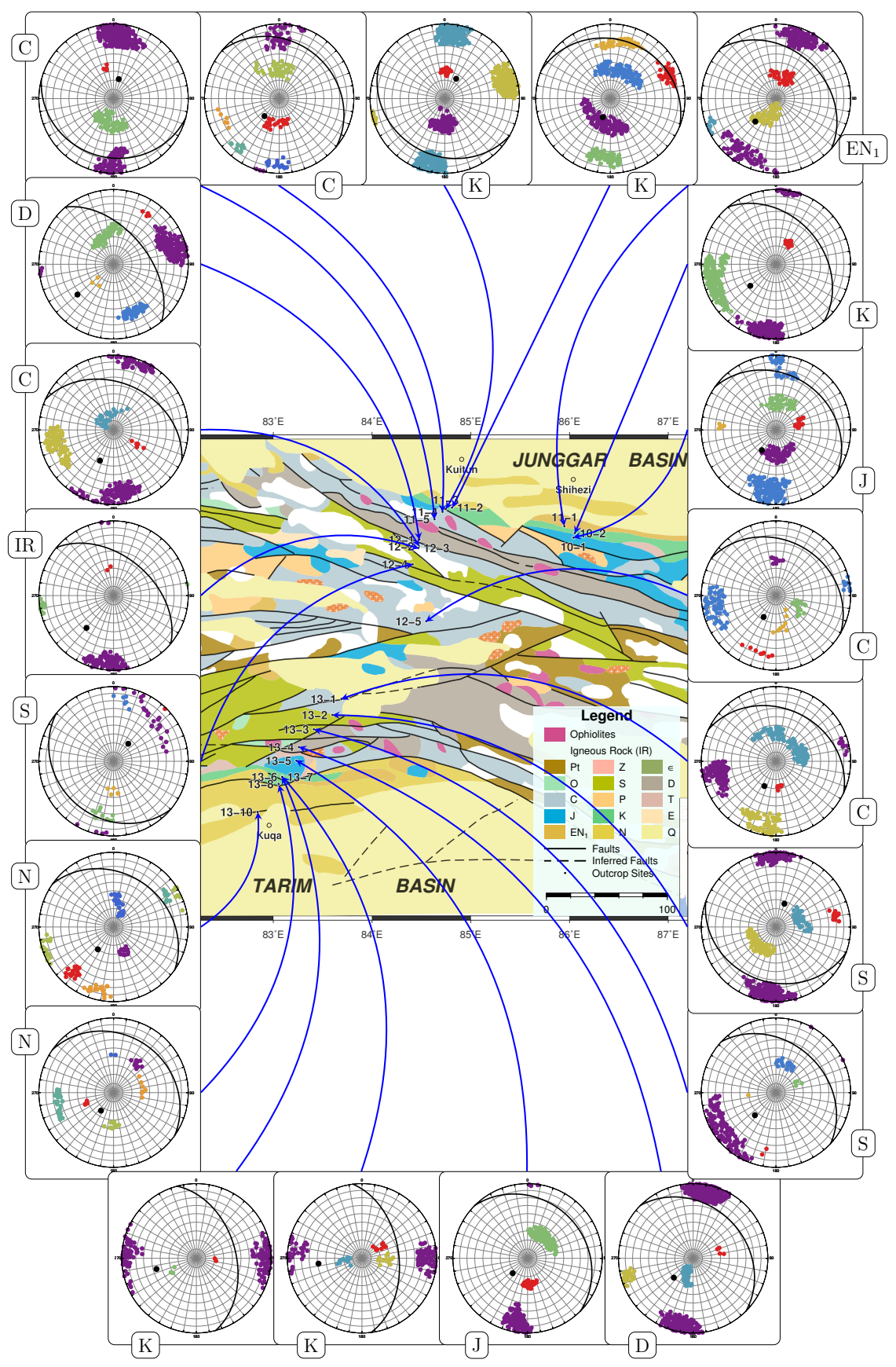

Figure 5: The clusters of paleostrain shortening directions for each outcrop and their linkage to the corresponding outcrop locations on the geological map (modified after Ma et al. (2002)). Different clusters are distinguished with different colors. The black dots (poles) and arcs represent the bedding surfaces. 
Table 1: The clusters of paleostrain shortening directions in poles plots, the poles plots of the corresponding fracture surfaces' occurrences and the corresponding fracture surfaces projected onto the outcrops with different colors assigned to different clusters. The black dots (poles) and arcs represent the bedding surfaces. The reference coordinate system: the green axis points north, the red axis points east and the blue axis points vertically up, each axis is 1 meter long. This table lists 5 example outcrops. For rest of the outcrops, please see the supporting information (Table S1).

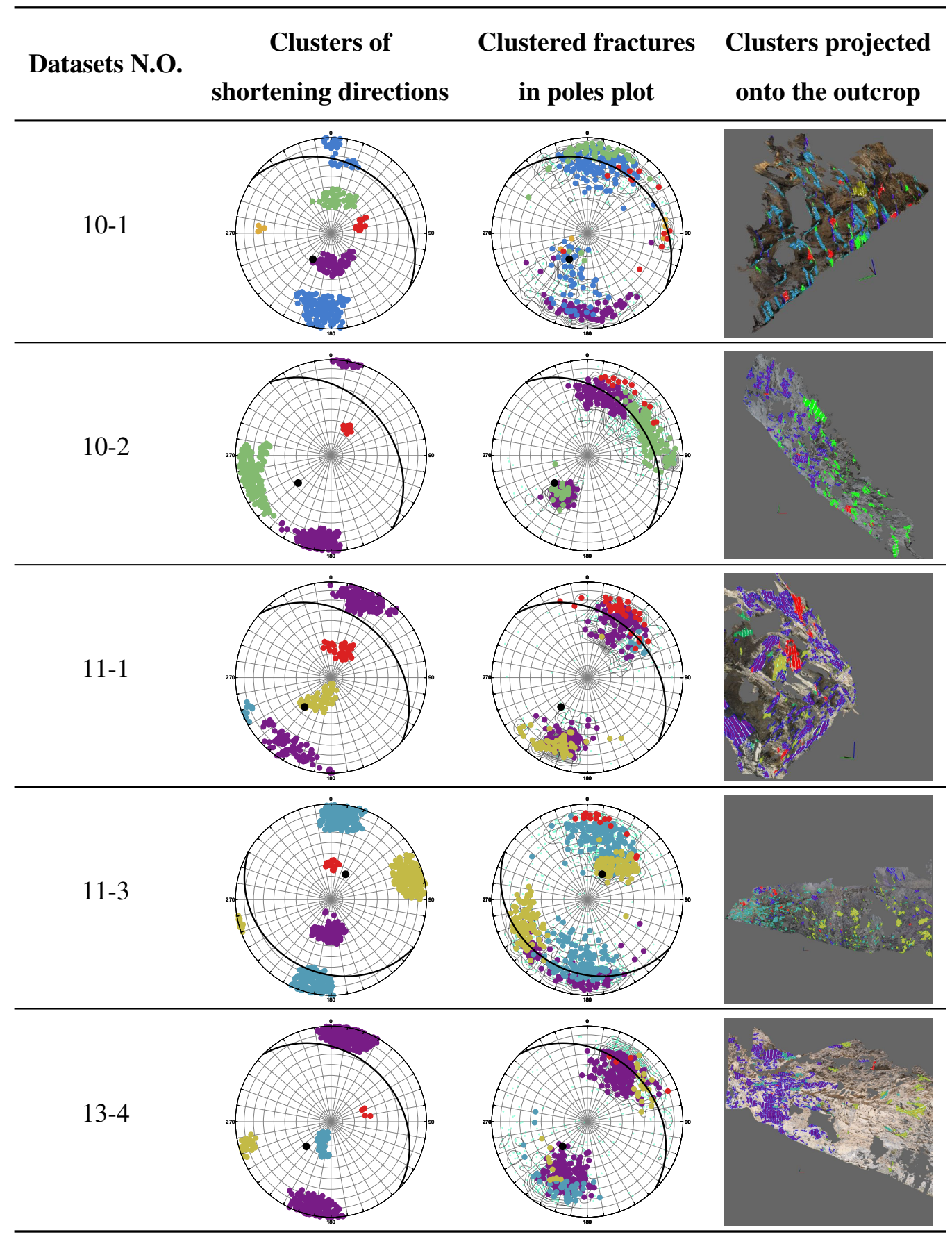




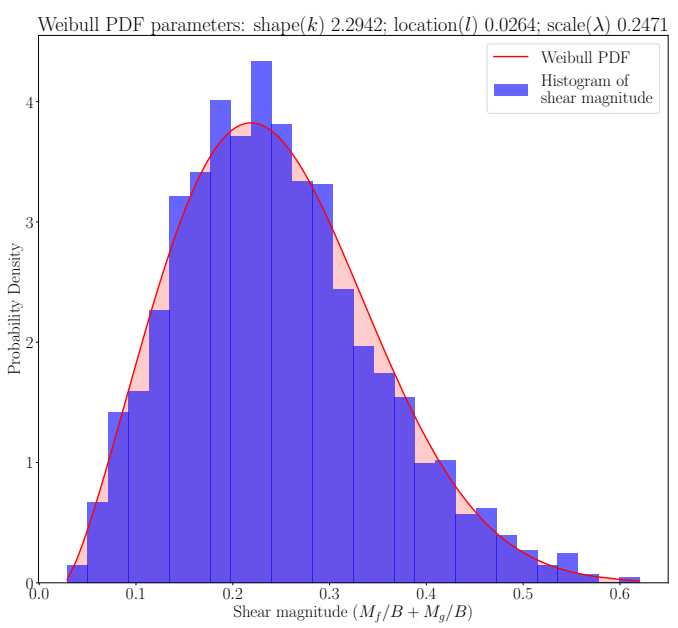

Outcrop 11-3

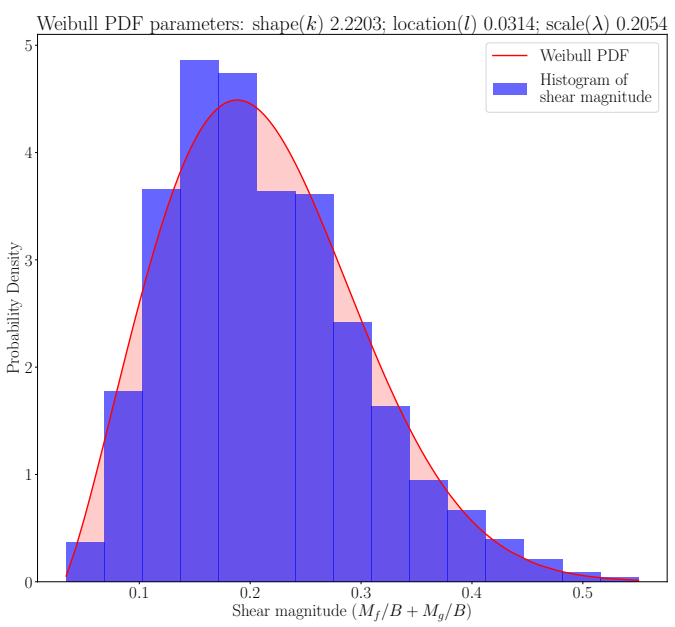

Outcrop 13-2

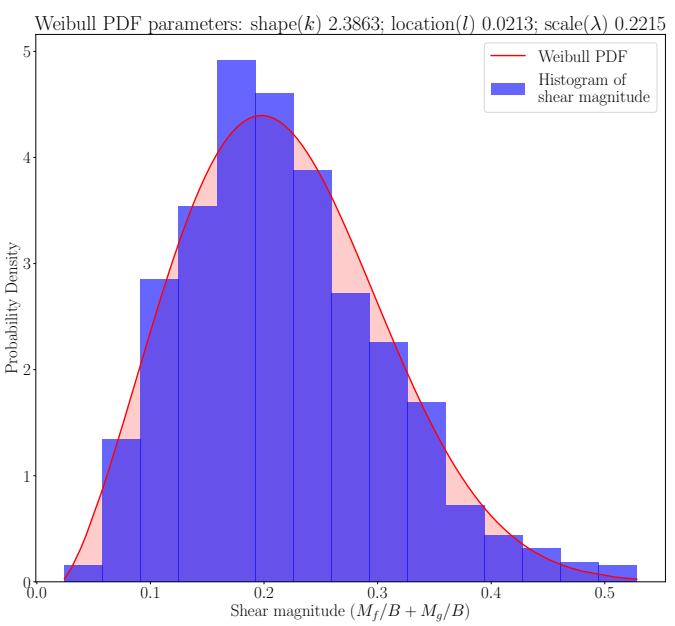

Outcrop 12-1

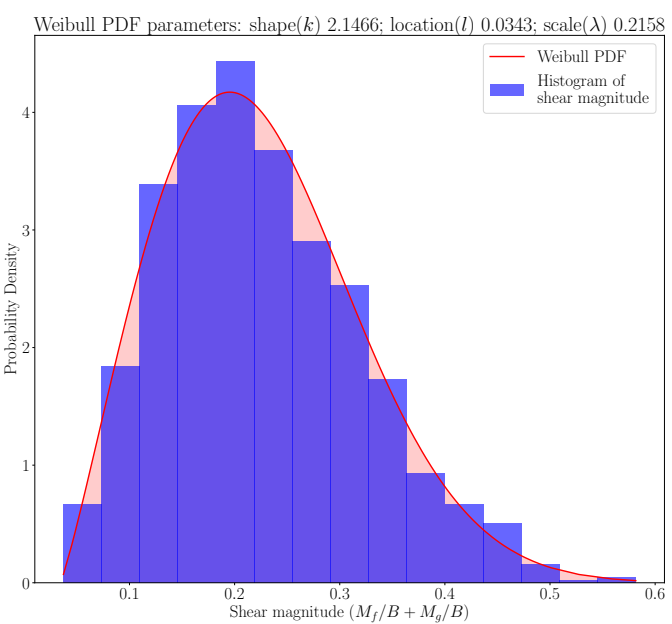

Outcrop 13-5

Figure 6: The histograms of the estimated relative slip $M_{S}=M_{f} / B+M_{g} / B$ on the fracture surfaces and the well fitted Weibull distributions.

\section{Conclusions}

Geologists have been trying to determine the paleostress history from evidence found in rocks for decades. Traditional paleostress inversion methods usually have assumptions that are to some extent controversial, and usually require a detailed field study with manually collected data after the overall geologic framework is understood. Recent development of techniques for automatic extraction of fracture surfaces from digital outcrop models and 
estimation of historical shear deformation on rock fractures can easily and automatically provide thousands of high quality fracture/fault slip data from just one single outcrop, which provides much more detailed information about the strain of the outcrop. Thus the new techniques provide a good opportunity to develop automatic and quantitative methods for deciphering more realistic paleostrains. In this paper, without the to some extent controversial assumptions in the traditional paleostress inversion methods, the local strain tensor is calculated for slip on each fracture from the outcrop, and then are grouped into populations corresponding to different strain events using a clustering analysis technique called DBSCAN.

The applications on outcrops in the eastern Tian Shan area give a clear picture of the late Cenozoic paleostrain variation over space and time: the clusters of paleostrain shortening directions from each outcrop are linked to the corresponding outcrop locations on the geological map, the far-field shortening directions in eastern Tian Shan changed from NESW during the early Pleistocene to N-S since the Middle Pleistocene. We propose that the strain regime change since the Middle Pleistocene could be related to the Tian Shan uplift since early Pleistocene. The high angle shortening groups seem to be caused by local strains and confined by the regional strains, as many outcrops show that surfaces corresponding to the high angle shortening groups are confined between fracture surfaces corresponding to the regional shortening groups. A model like the Riedel shear structures may be suitable to describe the regional-local strain relationships here. The high angle shortening groups may also be explained by that some of the more steeply dipped thrusting faults changed into normal faults when the ratio of the vertical stress to the horizontal tectonic stress becomes large enough. In a thrusting environment like the eastern Tian Shan, the paleostrain shortening events tend to use the slips on existing discontinuities like bedding surfaces to accomplish the shortening, even when the strikes of the existing discontinuities are not optimal for (perpendicular to) the shortening directions. The estimated relative slip $M_{S}$ on the fracture surfaces can be very well fitted by a Weibull distribution, and the parameters of this Weibull distribution may be related to the energy needed to make slip displacements 
on those fracture surfaces. Further researches should focus on this subject.

\section{Acknowledgments}

This research was funded by the State Key Program of National Natural Science Foundation of China (Grant no. 51934007) and the Fundamental Research Funds for the Central Universities (Grant no. 2020QN29). We would like to thank Professor Christopher H. Scholz, Professor William Ellsworth and Professor Roland Bürgmann for their valuable comments on important problems in this research. The editors and the anonymous reviewers made valuable comments and suggestions, which have greatly improved this paper. Readers can find the original outcrop point cloud data from https://figshare.com/ articles/Quantitatively-deciphered-paleostrain/10735988 (Wang, 2019).

\section{References}

Allen, M.B., Windley, B.F., Zhang, C., 1993. Palaeozoic collisional tectonics and magmatism of the chinese tien shan, central asia. Tectonophysics 220, 89-115.

Amrouch, K., Beaudoin, N., Lacombe, O., Bellahsen, N., Daniel, J.M., 2011. Paleostress magnitudes in folded sedimentary rocks. Geophysical Research Letters 38.

Amrouch, K., Lacombe, O., Bellahsen, N., Daniel, J.M., Callot, J.P., 2010. Stress and strain patterns, kinematics and deformation mechanisms in a basement-cored anticline: Sheep mountain anticline, wyoming. Tectonics 29.

Angelier, J., 1979. Determination of the mean principal directions of stresses for a given fault population. Tectonophysics 56, T17-T26.

Angelier, J., 1984. Tectonic analysis of fault slip data sets. Journal of Geophysical Research: Solid Earth 89, 5835-5848.

Angelier, J., 1989. From orientation to magnitudes in paleostress determinations using fault slip data. Journal of structural geology 11, 37-50. 
Angelier, J., 1990. Inversion of field data in fault tectonics to obtain the regional stressiii. a new rapid direct inversion method by analytical means. Geophysical Journal International $103,363-376$.

Angelier, J., Tarantola, A., Valette, B., Manoussis, S., 1982. Inversion of field data in fault tectonics to obtain the regional stressi. single phase fault populations: a new method of computing the stress tensor. Geophysical Journal International 69, 607-621.

Arboit, F., Amrouch, K., Collins, A.S., King, R., Morley, C., 2015. Determination of the tectonic evolution from fractures, faults, and calcite twins on the southwestern margin of the indochina block. Tectonics 34, 1576-1599.

Bott, M.H.P., 1959. The mechanics of oblique slip faulting. Geological Magazine 96, $109-117$.

Dehandschutter, B., Vysotsky, E., Delvaux, D., Klerkx, J., Buslov, M.M., Seleznev, V.S., De Batist, M., 2002. Structural evolution of the teletsk graben (russian altai). Tectonophysics 351, 139-167.

Delvaux, D., Cloetingh, S., Beekman, F., Sokoutis, D., Burov, E., Buslov, M.M., Abdrakhmatov, K.E., 2013. Basin evolution in a folding lithosphere: Altai-sayan and tien shan belts in central asia. Tectonophysics 602, 194-222.

Delvaux, D., Moeys, R., Stapel, G., Petit, C., Levi, K., Miroshnichenko, A., Ruzhich, V., San'kov, V., 1997. Paleostress reconstructions and geodynamics of the baikal region, central asia, part 2. cenozoic rifting. Tectonophysics 282, 1-38.

Ester, M., Kriegel, H.P., Sander, J., Xu, X., 1996. A density-based algorithm for discovering clusters in large spatial databases with noise, in: Proceedings of the Second International Conference on Knowledge Discovery and Data Mining, AAAI Press. p. 226231.

Etchecopar, A., Vasseur, G., Daignieres, M., 1981. An inverse problem in microtectonics 
for the determination of stress tensors from fault striation analysis. Journal of Structural Geology 3, 51-65.

Fu, B., Lin, A., Kano, K.I., Maruyama, T., Guo, J., 2003. Quaternary folding of the eastern tian shan, northwest china. Tectonophysics 369, 79-101.

Grasselli, G., Wirth, J., Egger, P., 2002. Quantitative three-dimensional description of a rough surface and parameter evolution with shearing. International Journal of Rock Mechanics and Mining Sciences 39, 789 - 800. doi:https://doi.org/10.1016/ S1365-1609(02)00070-9.

Hancock, P.L., 1985. Brittle microtectonics: principles and practice. Journal of structural geology 7, 437-457.

Hashimoto, Y., Stipp, M., Lewis, J.C., Wuttke, F., 2019. Paleo-stress orientations and magnitudes from triaxial testing and stress inversion analysis in nankai accretionary prism sediments. Progress in Earth and Planetary Science 6, 3.

Hippolyte, J.C., Bergerat, F., Gordon, M.B., Bellier, O., Espurt, N., 2012. Keys and pitfalls in mesoscale fault analysis and paleostress reconstructions, the use of angelier's methods. Tectonophysics 581, 144-162.

Homberg, C., Bergerat, F., Philippe, Y., Lacombe, O., Angelier, J., 2002. Structural inheritance and cenozoic stress fields in the jura fold-and-thrust belt (france). Tectonophysics 357, 137 - 158. doi:https: //doi .org/10 . 1016/S0040-1951(Q2)00366-9.

Homberg, C., Lacombe, O., Angelier, J., Bergerat, F., 1999. New constraints for indentation mechanisms in arcuate belts from the Jura Mountains, France. Geology 27, 827-830. doi:10 . 1130/0091-7613(1999)027<0827: NCFIMI>2 . 3 . C0;2, arXiv:https://pubs.geoscienceworld.org/geology/article-pdf/27/9/827/3518552/i0091

Kaven, J.O., Maerten, F., Pollard, D.D., 2011. Mechanical analysis of fault slip data: Implications for paleostress analysis. Journal of structural geology 33, 78-91. 
Lacombe, O., 2012. Do fault slip data inversions actually yield paleostresses that can be compared with contemporary stresses? a critical discussion. Comptes Rendus Geoscience 344, 159-173.

Lacombe, O., Mouthereau, F., Kargar, S., Meyer, B., 2006. Late cenozoic and modern stress fields in the western fars (iran): Implications for the tectonic and kinematic evolution of central zagros. Tectonics 25. doi:10.1029/2005TC001831, arXiv:https://agupubs . onlinelibrary.wiley.com/doi/pdf/10.1029/2005TC001831.

Ma, L., Qiao, X., Min, L., Fan, B., Ding, X., et al., 2002. Geological Atlas of China. Beijing: Geological Publishing House.

Maestro, A., Ruano, P., Torres Carbonell, P., Bohoyo, F., Galindo-Zaldívar, J., Pedrera, A., Ruiz-Constán, A., González-Castillo, L., Ibarra, P., López-Martínez, J., 2019. Stress field evolution of the southernmost andean cordillera from paleostress analysis (argentine tierra del fuego). Tectonics 38, 7-25. doi:10.1029/2018TC005158, arXiv:https://agupubs . onlinelibrary . wiley . com/doi/pdf/10.1029/2018TC005158.

Molnar, P., Brown, E.T., Burchfiel, B.C., Deng, Q., Feng, X., Li, J., Raisbeck, G.M., Shi, J., Wu, Z., Yiou, F., et al., 1994. Quaternary climate change and the formation of river terraces across growing anticlines on the north flank of the tien shan, china. The Journal of Geology 102, 583-602.

Molnar, P., Deng, Q., 1984. Faulting associated with large earthquakes and the average rate of deformation in central and eastern asia. Journal of Geophysical Research: Solid Earth $89,6203-6227$.

Molnar, P., Ghose, S., 2000. Seismic moments of major earthquakes and the rate of shortening across the tien shan. Geophysical Research Letters 27, 2377-2380.

Molnar, P., Tapponnier, P., 1975. Cenozoic tectonics of asia: effects of a continental collision. science 189, 419-426. 
$\mathrm{Ni}$ J., 1978. Contemporary tectonics in the tien shan region. Earth and Planetary Science Letters 41, 347-354.

Qiao, Q., Huang, B., Biggin, A.J., Piper, J.D.A., 2017. Late cenozoic evolution in the pamirtian shan convergence: New chronological constraints from the magnetostratigraphic record of the southwestern tianshan foreland basin (ulugqat area). Tectonophysics 717, $51-64$.

Radaideh, O.M.A., Melichar, R., 2015. Tectonic paleostress fields in the southwestern part of jordan: New insights from the fault slip data in the southeastern flank of the dead sea fault zone. Tectonics 34, 1863-1891. doi:10.1002/2015TC003919, arXiv:https://agupubs . onlinelibrary . wiley.com/doi/pdf/10 . 1002/2015TC003919.

Riller, U., Clark, M.D., Daxberger, H., Doman, D., Lenauer, I., Plath, S., Santimano, T., 2017. Fault-slip inversions: Their importance in terms of strain, heterogeneity, and kinematics of brittle deformation. Journal of Structural Geology 101, 80-95.

Sagy, A., Brodsky, E.E., Axen, G.J., 2007. Evolution of fault-surface roughness with slip. Geology 35, 283-286.

Shimizu, I., 2008. Theories and applicability of grain size piezometers: The role of dynamic recrystallization mechanisms. Journal of Structural Geology 30, 899-917.

Simón, J.L., 2019. Forty years of paleostress analysis: has it attained maturity? Journal of Structural Geology 125, 124-133.

Sperner, B., Zweigel, P., 2010. A plea for more caution in fault-slip analysis. Tectonophysics 482, 29-41.

Stipp, M., Tullis, J., 2003. The recrystallized grain size piezometer for quartz. Geophysical Research Letters 30. 
Tapponnier, P., Molnar, P., 1979. Active faulting and cenozoic tectonics of the tien shan, mongolia, and baykal regions. Journal of Geophysical Research: Solid Earth 84, 34253459.

Tian, X., Zhao, D., Zhang, H., Tian, Y., Zhang, Z., 2010. Mantle transition zone topography and structure beneath the central tien shan orogenic belt. Journal of Geophysical Research: Solid Earth 115.

Twiss, R.J., Unruh, J.R., 1998. Analysis of fault slip inversions: Do they constrain stress or strain rate? Journal of Geophysical Research: Solid Earth 103, 12205-12222.

Vergnolle, M., Calais, E., Dong, L., 2007. Dynamics of continental deformation in asia. Journal of Geophysical Research: Solid Earth 112.

Wallace, R.E., 1951. Geometry of shearing stress and relation to faulting. The Journal of geology 59, 118-130.

Wang, X., 2019. Quantitatively-deciphered-paleostrain. URL: https://figshare. com/articles/Quantitatively-deciphered-paleostrain/10735988/1, doi:10.6084/m9. figshare. 10735988 .v1.

Wang, X., Qin, Y., Yin, Z., Zou, L., Shen, X., 2019. Historical shear deformation of rock fractures derived from digital outcrop models and its implications on the development of fracture systems. International Journal of Rock Mechanics and Mining Sciences 114, $122-130$.

Wang, X., Zou, L., Shen, X., Ren, Y., Qin, Y., 2017. A region-growing approach for automatic outcrop fracture extraction from a three-dimensional point cloud. Computers \& geosciences 99, 100-106.

Windley, B.F., Allen, M.B., Zhang, C., Zhao, Z., Wang, G., 1990. Paleozoic accretion and cenozoic redeformation of the chinese tien shan range, central asia. Geology 18, $128-131$. 
Yang, S., Li, J., Wang, Q., 2008. The deformation pattern and fault rate in the tianshan mountains inferred from gps observations. Science in China Series D: Earth Sciences $51,1064-1080$.

Zubovich, A.V., Wang, X., Scherba, Y.G., Schelochkov, G.G., Reilinger, R., Reigber, C., Mosienko, O.I., Molnar, P., Michajljow, W., Makarov, V.I., et al., 2010. Gps velocity field for the tien shan and surrounding regions. Tectonics 29. 


\section{Appendix: Supplementary materials}

Table S1: The clusters of paleostrain shortening directions in poles plots, the poles plots of the corresponding fracture surfaces' occurrences and the corresponding fracture surfaces projected onto the outcrops with different colors assigned to different clusters. The black dots (poles) and arcs represent the bedding surfaces. The reference coordinate system: the green axis points north, the red axis points east and the blue axis points vertically up, each axis is 1 meter long.

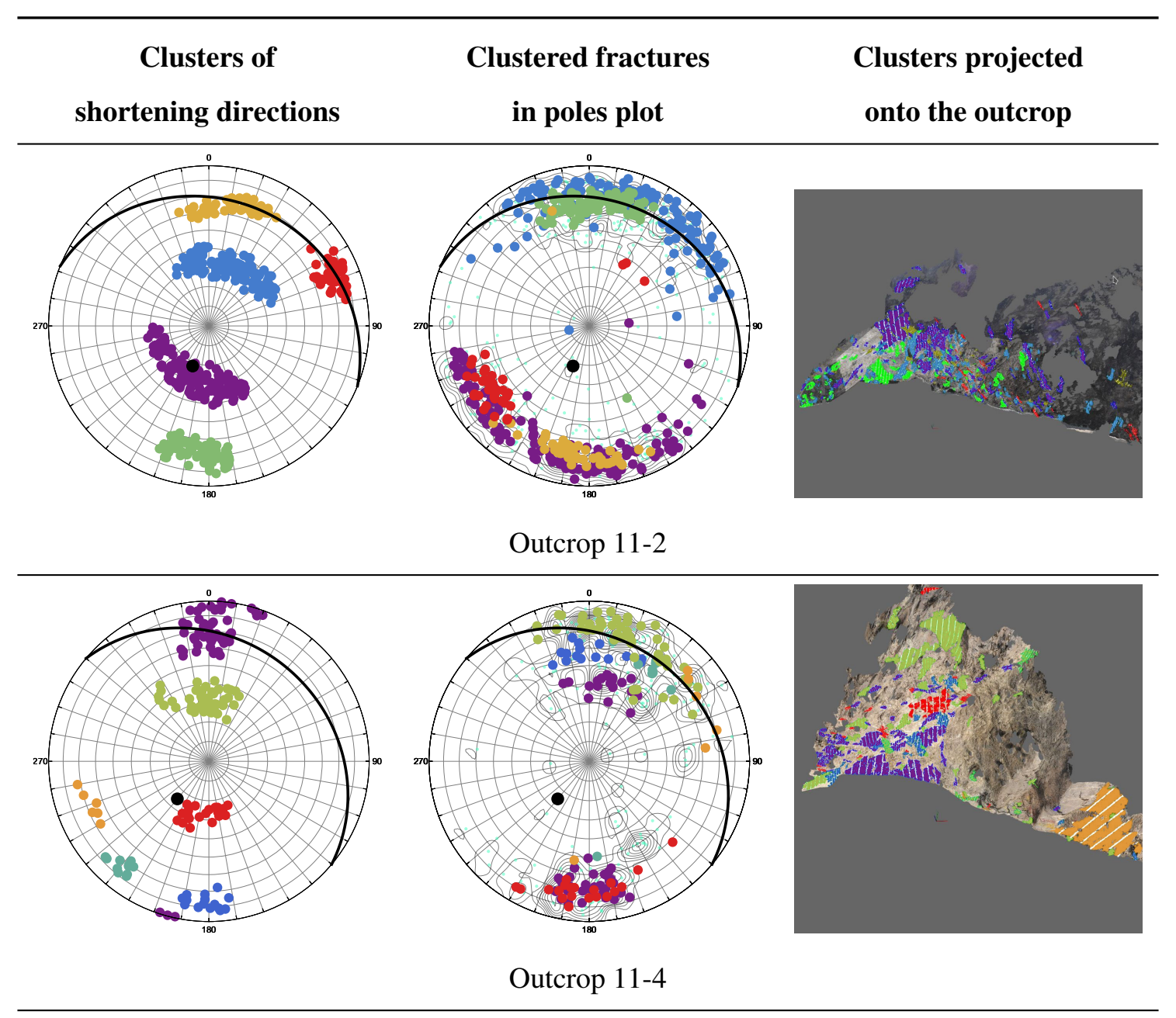

Continued on next page 
Table S1 - Continued from previous page

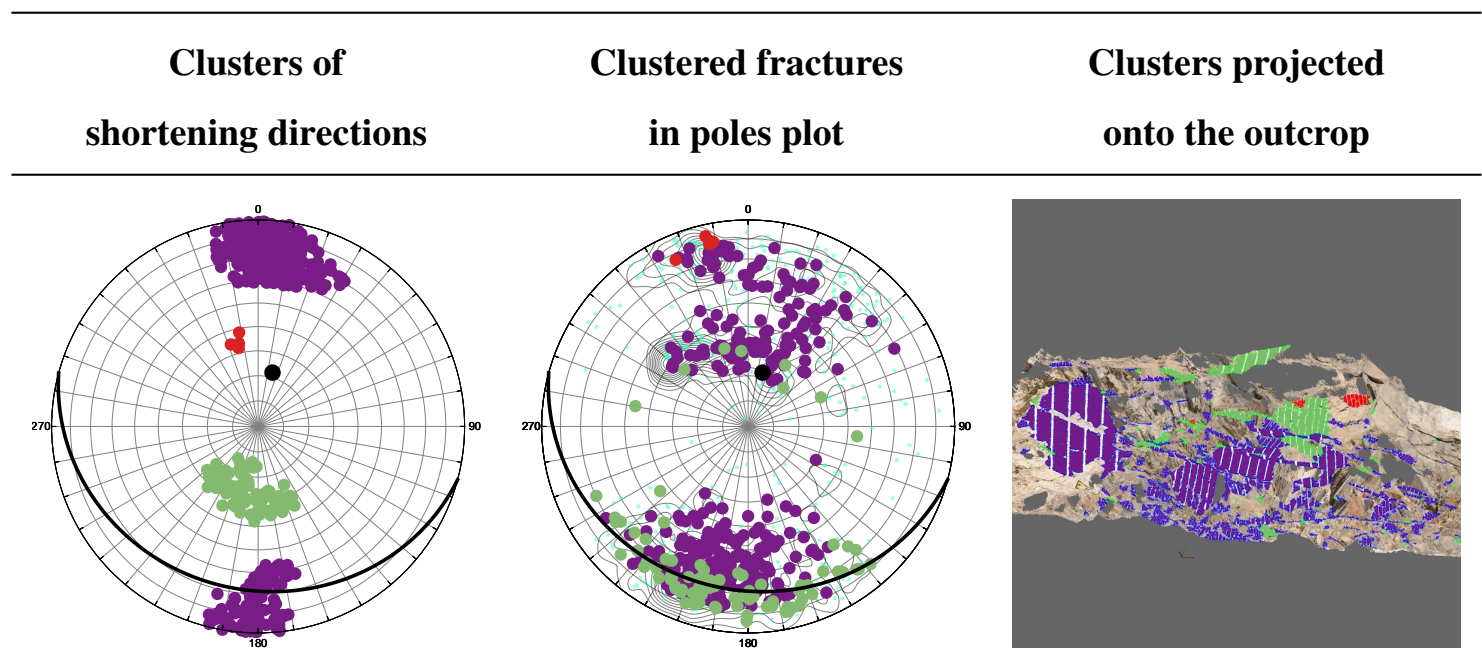

Outcrop 11-5

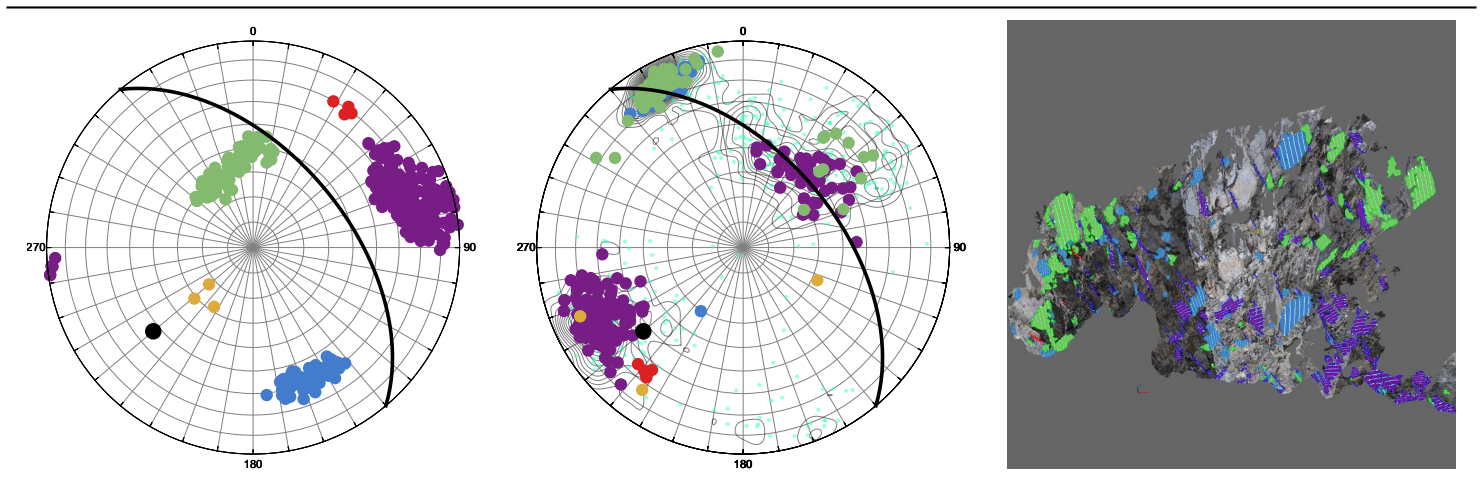

Outcrop 12-1
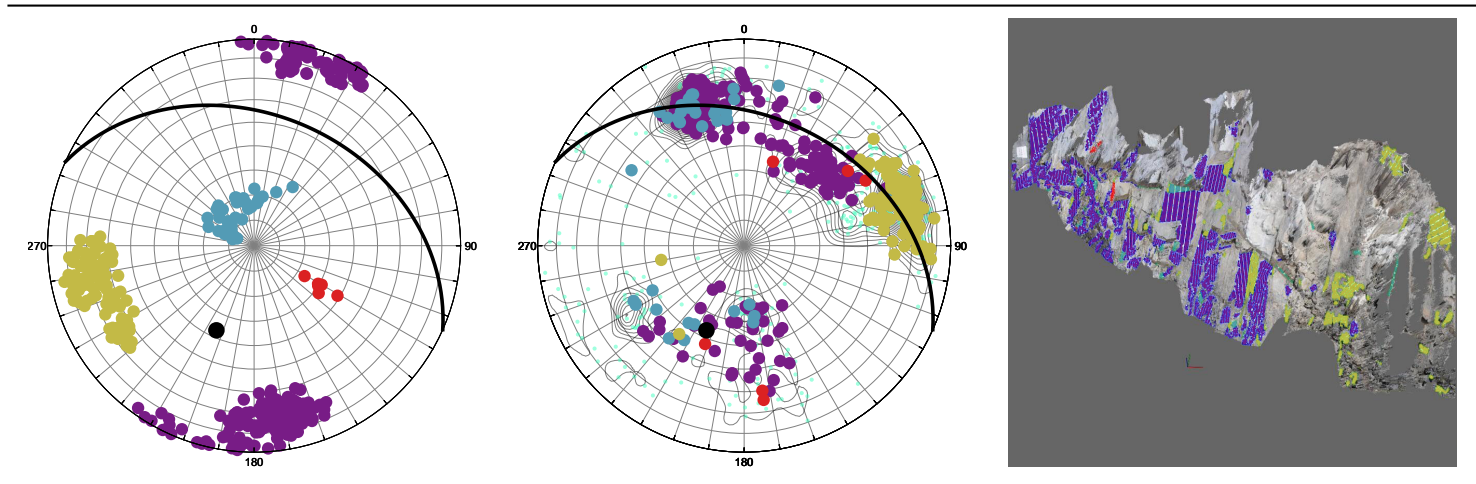

Outcrop 12-2

Continued on next page 
Table S1 - Continued from previous page

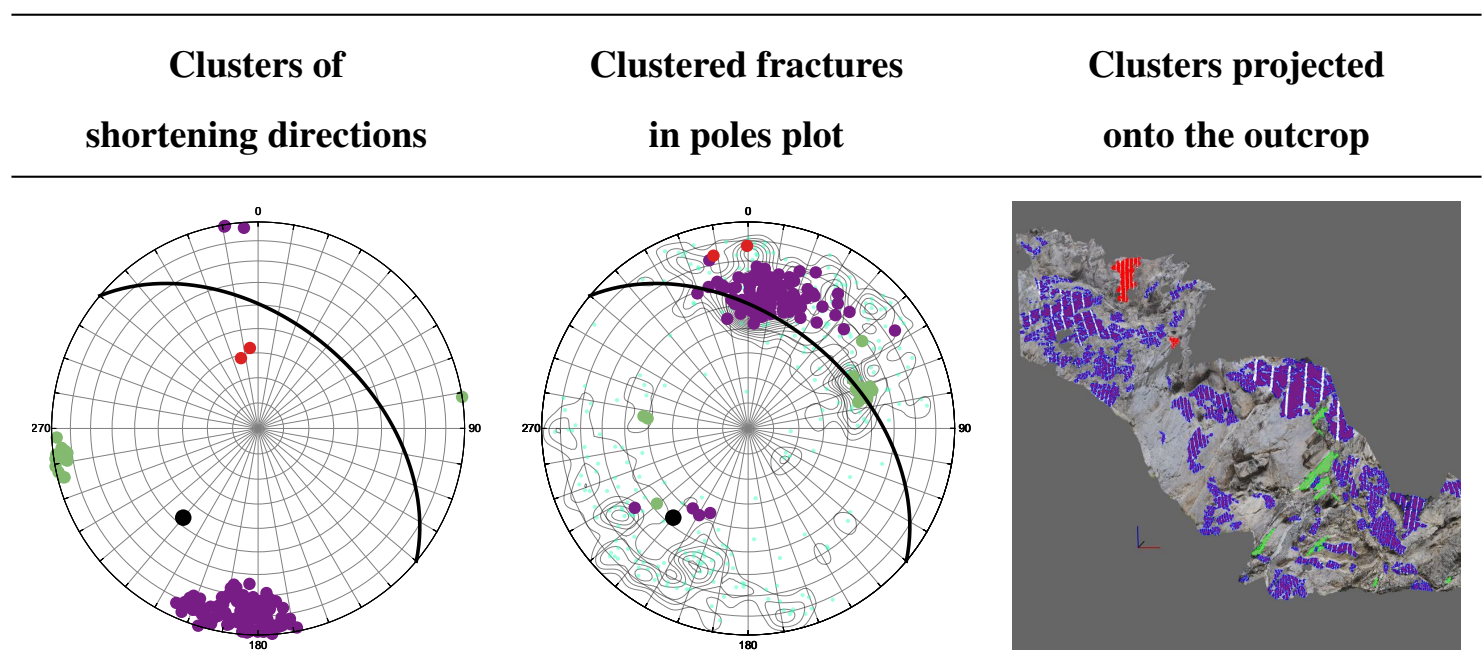

Outcrop 12-3

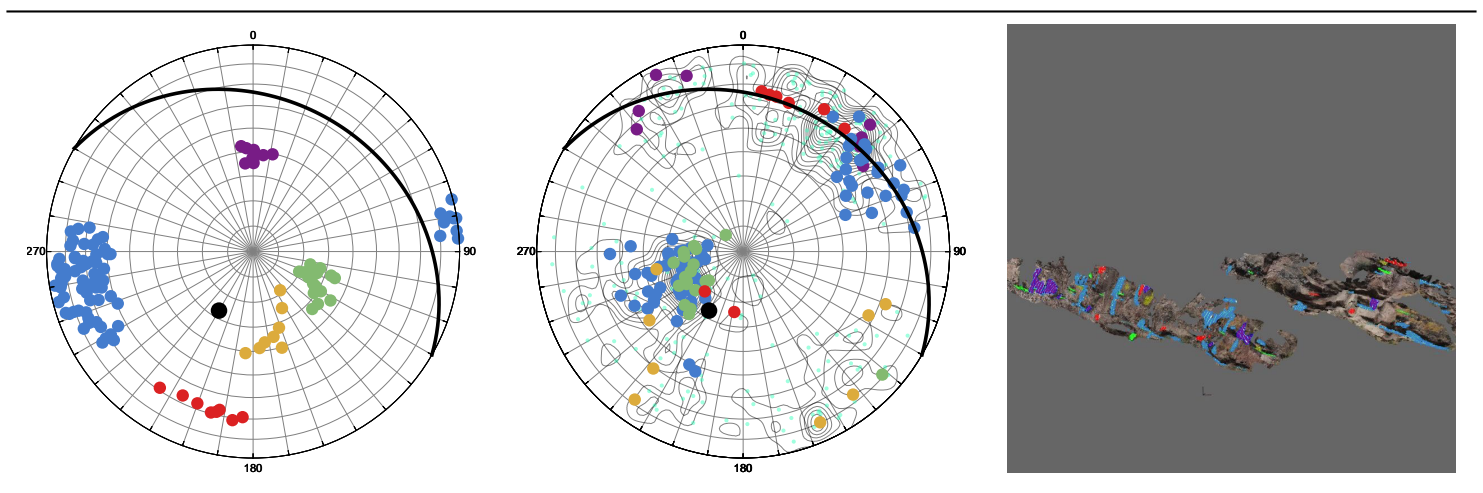

Outcrop 12-5
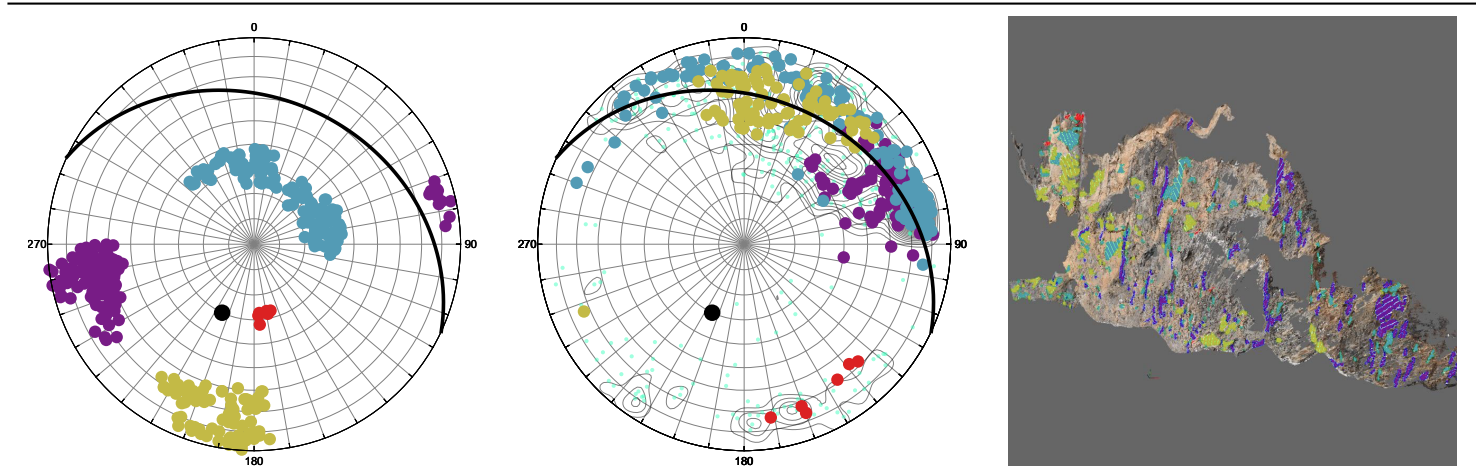

Outcrop 13-1

Continued on next page 
Table S1 - Continued from previous page

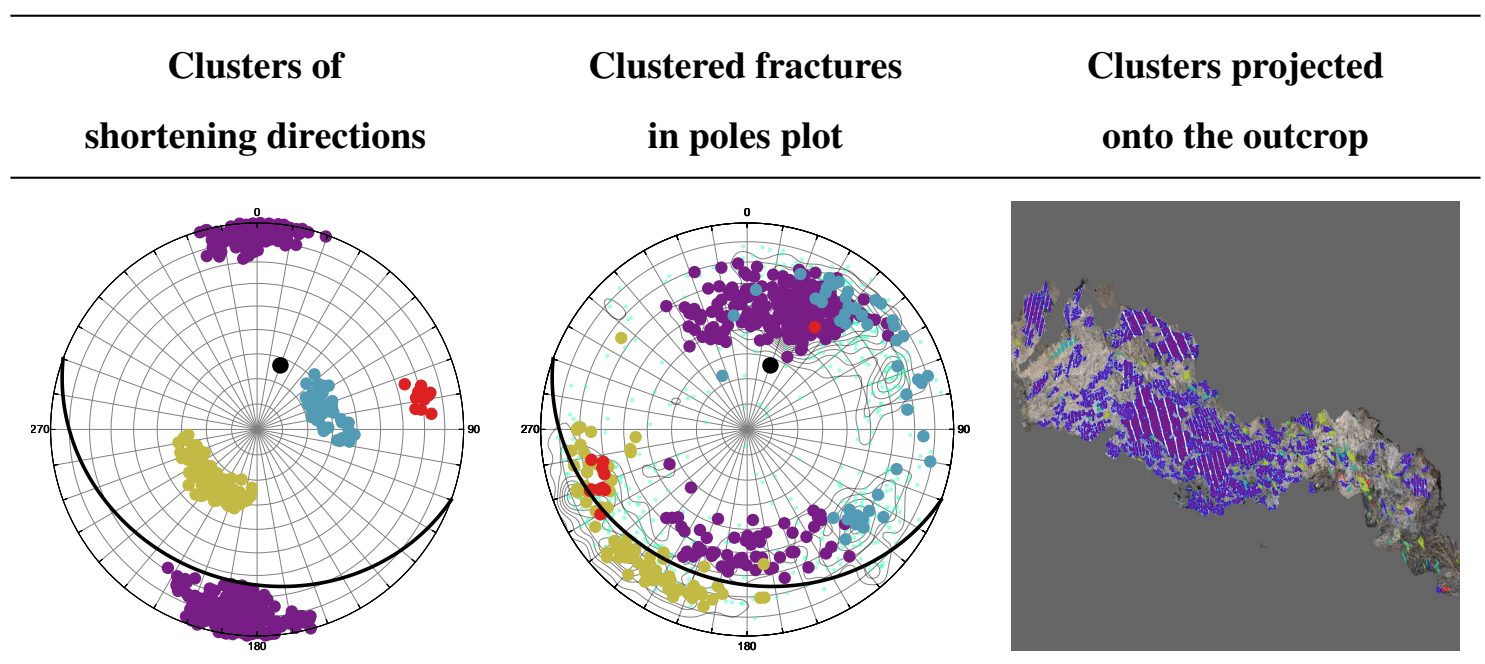

Outcrop 13-2

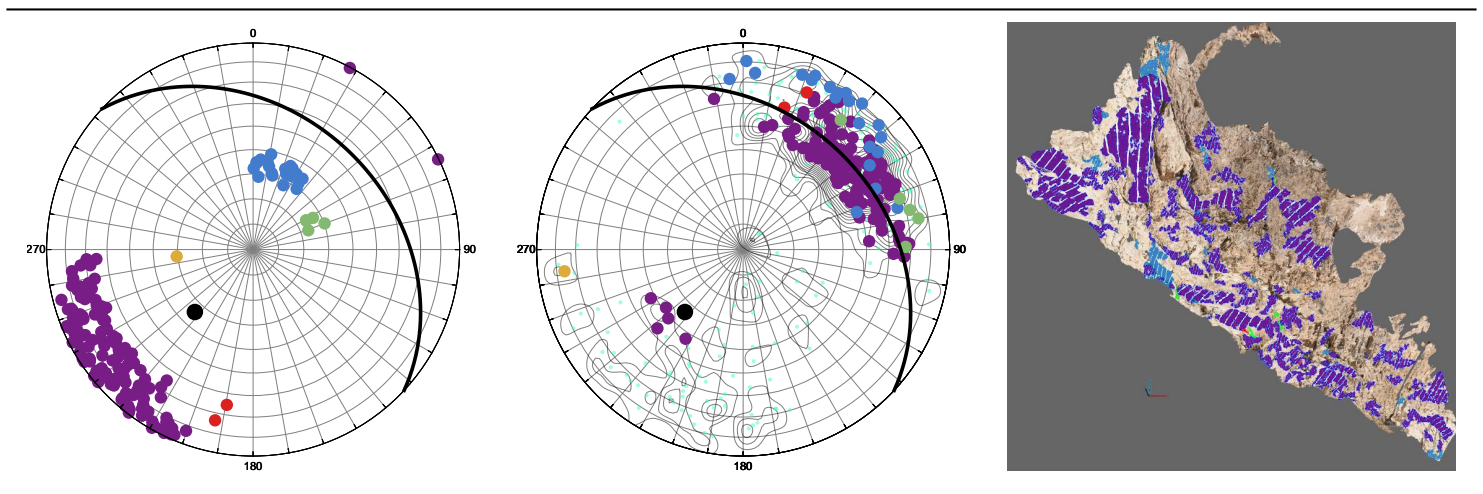

Outcrop 13-3
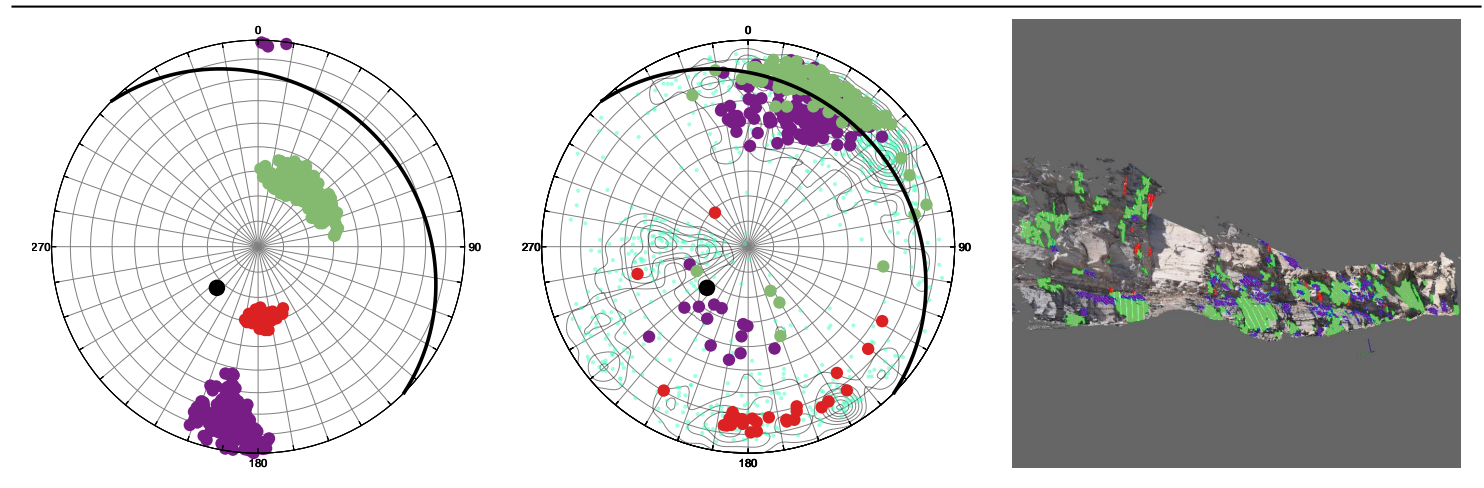

Outcrop 13-5

Continued on next page 
Table S1 - Continued from previous page

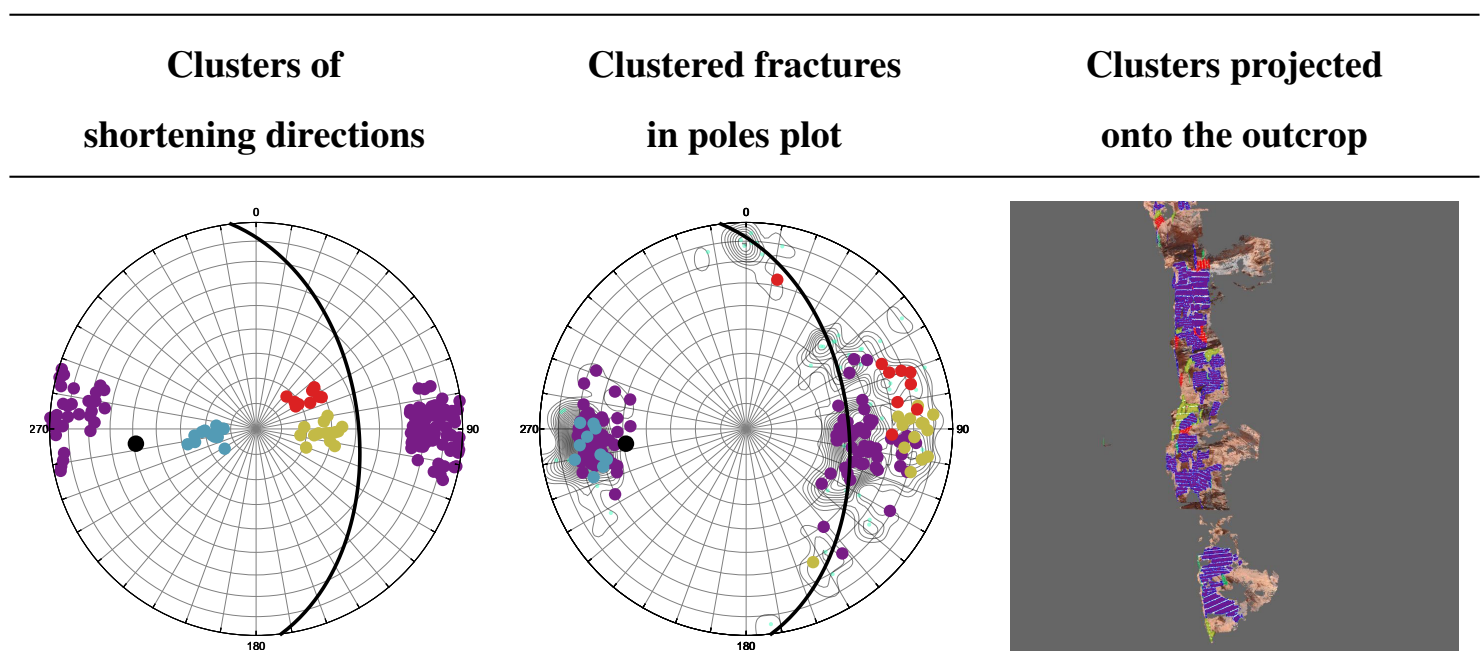

Outcrop 13-6

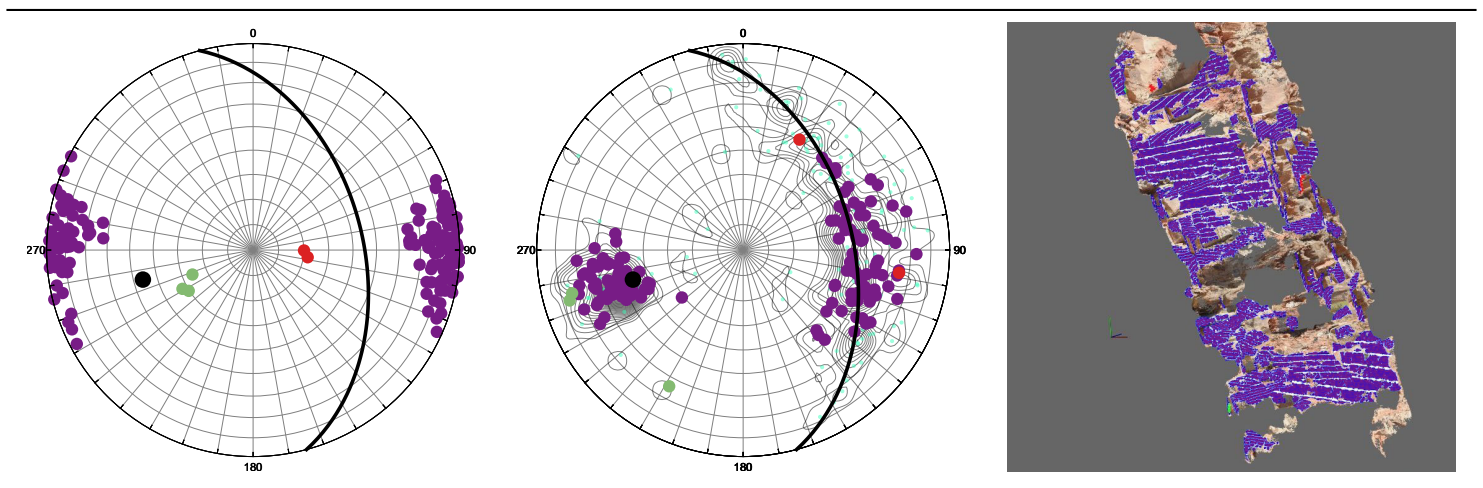

Outcrop 13-7

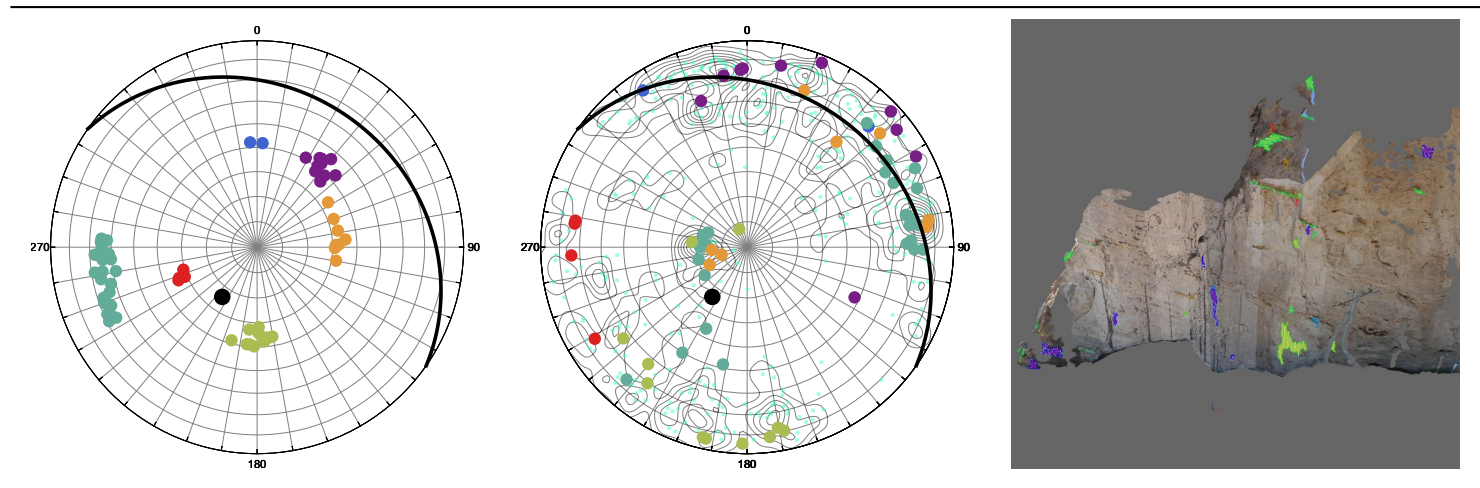

Outcrop 13-8

Continued on next page 
Table S1 - Continued from previous page

\begin{tabular}{ccc}
$\begin{array}{c}\text { Clusters of } \\
\text { shortening directions }\end{array}$ & $\begin{array}{c}\text { Clustered fractures } \\
\text { in poles plot }\end{array}$ & $\begin{array}{c}\text { Clusters projected } \\
\text { onto the outcrop }\end{array}$ \\
\hline & Outcrop 13-10
\end{tabular}

